\title{
Optimal thermo aerodynamic performance of s-shaped baffled channels
}

\author{
Y. Menni ${ }^{1 *}$, A. Azzi ${ }^{1,2}$ and A. J. Chamkha ${ }^{3,4}$ \\ ${ }^{1}$ Unit of Research on Materials and Renewable Energies, Department of Physics, \\ Faculty of Sciences, Abou Bekr Belkaid University, BP 119-13000-Tlemcen, Algeria \\ Phone: +213 43215 890; Fax: +213 43215889 \\ ${ }^{2}$ Department of Mechanical Engineering, Faculty of Technology, \\ Abou Bekr Belkaid University, BP 230-13000-Tlemcen, Algeria \\ ${ }^{3}$ Mechanical Engineering Department, Prince Sultan Endowment for Energy and Environment, \\ Prince Mohammad Bin Fahd University, Al-Khobar 31952, Saudi Arabia \\ ${ }^{4}$ RAK Research and Innovation Center, American University of Ras Al Khaimah, \\ United Arab Emirates \\ *Email : menniyounes.cfd@gmail.com
}

\begin{abstract}
This manuscript presents a numerical analysis of fluid flow and heat transfer in rectangular cross section channels with and without baffles using air as the working fluid at Reynolds numbers ranging from 12,000 to 32,000. Four various channel geometries were studied in this analysis. In the first case, a smooth channel with no baffle was analyzed. In the second case, a flat rectangular baffled channel was investigated, and in the third case, S-shaped baffled channels were examined (i.e., S-baffles pointed towards the upstream end: called S-upstream baffles; and S-baffles pointed towards the downstream end: called S-downstream baffles). The Commercial CFD software FLUENT was employed to simulate the air flow and thermal aspects in the whole domain investigated based on finite volume approach. The thermo aerodynamic performance evaluations were considered in three parts; thermal transfer, skin friction loss and thermal enhancement factor in terms of $\mathrm{Nu} / \mathrm{Nu}_{0}, \mathrm{f} / \mathrm{f}_{0}$, and $\mathrm{TEF}$, respectively. In general, the normalized average Nusselt number and normalized friction factor tend to augment with the increase of the Reynolds number for all channel situations. Over range studies, the improvements are found to be around $1.939-4.582$ and 3.319 - 32.336 times upper than the smooth air channel for $\mathrm{Nu}$ and $\mathrm{f}$, respectively. In a comparison with the flat rectangular baffle, the $\mathrm{Nu} / \mathrm{Nu}_{0}$ and $\mathrm{f} / \mathrm{f}_{0}$ values increase in the cases of S-upstream baffle by $14.855 \%$ and $26.282 \%$, respectively at $\mathrm{Re}=32,000$. However, the $\mathrm{Nu} / \mathrm{Nu}_{0}$ and $\mathrm{f} / \mathrm{f}_{0}$ values decrease by $7.442 \%$ and $41.481 \%$ when the baffle shape is S-downstream at the same Re value, respectively.
\end{abstract}

Keywords: Turbulence; Reynolds number; S-shaped baffles; CFD; Air.

\section{INTRODUCTION}

The success of the solar energy applications is closely related to the performance of the collectors which convert it. For the collectors whose caloporting fluid is water; thermal transfer is made suitably because water is a good conductor of heat. However, for solar air collectors, heat transfer is low [1]. Numerous techniques to improve thermal transfer in solar air collectors are reported in the literature [2-10]. One of these techniques is the insertion of baffles and fins in the air channel duct of the collector, which disturb the boundary layer growth and thus improve the thermal transfer. Promvonge et al. [11] carried out a numerical investigation of laminar periodic flow and heat 
transfer in a three-dimensional isothermal-wall square channel fitted with $45^{\circ}$ inclined baffles on one channel wall. Effects of flow blockage ratios on heat transfer and pressure loss in the square channel were examined and also compared with the typical case of the transverse baffle. Liu and Wang [12] presented a novel design of the ribbed channel, which is here called semi attached ribdesign. The ribs were perforated at the rib corners to form two rectangular holes, so a portion of the fluid can pass through the holes. Five different structures of the rib (width ratios of channel to hole) and two positions (transverse rib and $45^{\circ}$ angled ribs) were analyzed. Mellal et al. [13] investigated a three-dimensional numerical simulation of turbulent fluid flow and heat transfer in the shell side of a shell and tube heat exchanger (STHE). Three geometrical configurations with different baffles spacing were realized, which were: $106.6,80$, and $64 \mathrm{~mm}$. These values correspond respectively to the baffle numbers: 6,8 and 10 baffles. Effects of the baffle orientation angles $\left(45^{\circ}, 60^{\circ}, 90^{\circ}, 120^{\circ}\right.$, $150^{\circ}$ and $180^{\circ}$ ) were also studied. Menasria et al. [14] numerically investigated the turbulent flow and convective heat transfer of air inside channel of rectangular cross-section, containing rectangular baffles with inclined upper part planted on the opposite surface of absorber plate under solar air heater boundary conditions. Mokhtari et al. [15] numerically characterized and studied the mixed convection of a three-dimensional square duct with various arrangements of fins in both laminar and turbulent flow. This study focused on the ability of fin arrangements to enhance a heat transfer while flow was incompressible and the fluid was air. Sahel et al. [16] carried out a numerical study to investigate the turbulent flows and heat transfer characteristics in a rectangular channel fitted with two baffles placed on the upper and lower walls. These baffles were perforated by a row of four holes at three different positions. These positions were characterized by a ratio called the Pores Axis Ratio (PAR) which was taken equal to 0.190, 0.425 or 0.660. Yongsiri et al. [17] presented the results of numerical study of turbulent flow and heat transfer in a channel with inclined detached-ribs. Ary et al. [18] numerically and experimentally checked out the effect of a number of inclined perforated baffles on the flow patterns and heat transfer in the rectangular channel with different types of baffles. Dutta and Hossain [19] investigated the local heat transfer characteristics and the associated frictional head loss in a rectangular channel with inclined solid and perforated baffles. A combination of two baffles of same overall size was used in this experiment. The upstream baffle was attached to the top heated surface, while the position, orientation, and the shape of the other baffle were varied to identify the optimum configuration for enhanced heat transfer. Nuntadusit et al. [20] presented the heat transfer and flow characteristics in a channel with different types of transverse perforated ribs. The effects of perforation/hole inclination angle and a location of hole on the rib were examined. A detailed examination of the impact of the obstacle geometry reconfiguration, has been conducted by other authors, on the fluid flow and heat transfer characteristics in some particular cases of air flow geometry, for example simple [21], trapezoidal [22], cascaded [23], helical [24], diamond [25], waisted [26], U-shaped [27], double V-shaped [28], L-shaped [29], V-shaped [30], Z-shaped [31]. Different geometry parameters and various operating conditions were used in the previous studies. Other similar works can be found in the literature, i.e., Tahseen et al. [32], Gilani et al. [33], Al-Kayiem et al. [34], Hing et al. [35], and Neel Armstrong et al. [36]. They studied the heat transfer and fluid flows using numerical and experimental techniques.

Thermal transfer improvement in rectangular air channels by inserting baffles is reported in this paper. The impact of the channel geometry reconfiguration on the fluid flow and heat transfer improvement is investigated in detail through this analysis. Four various channel configurations are considered. The analyses are conducted with the Commercial CFD software FLUENT using the finite volume method, for Reynolds number varying from 12,000 to 32,000. The numerical results are presented in terms of streamlines, velocity-magnitude, $\mathrm{x}$-velocity, $\mathrm{y}$-velocity, dynamic pressure coefficient, turbulent kinetic energy, turbulent viscosity, turbulent intensity, temperature field, coefficient and factor of normalized skin friction, local and average numbers of normalized Nusselt, and thermal performance factor. 


\section{PHYSICAL MODEL}

\section{Problem Statement}

Figure 1 depicts a schematic representation of the physical model. Demartini et al. [21] conducted an experimental analysis which served as the basis for the detailed structural parameters used.

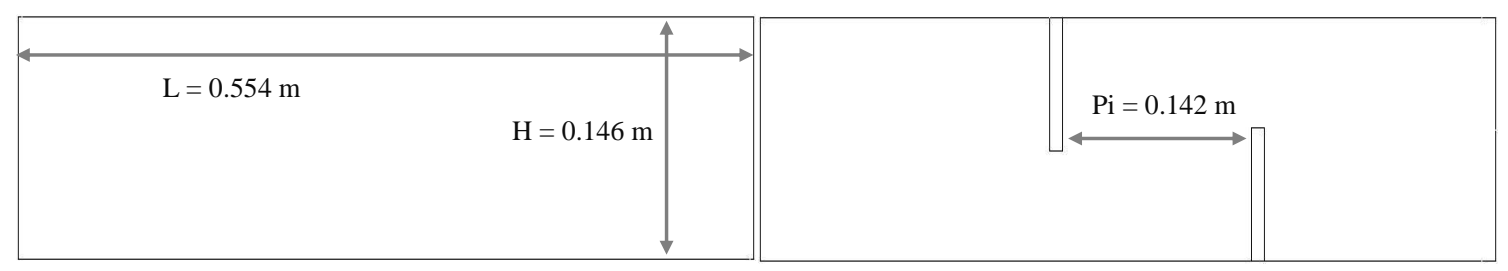

(a)

(b)

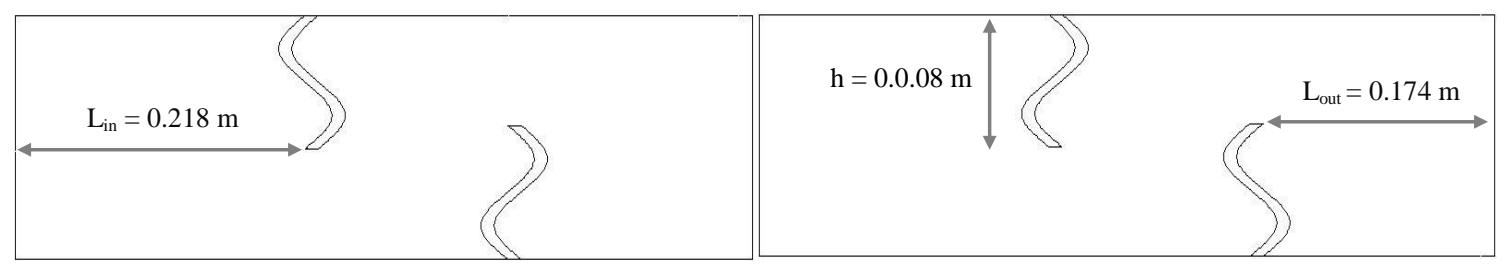

(c)

(d)

Figure 1. Channels under investigation: (a) smooth channel with no baffle, (b) flat rectangular baffled channel, (c) S-upstream baffled channel, and (d) S-downstream baffled channel.

The computational analysis is performed in a two-dimensional field, which represents constant temperature-surfaced rectangular cross section channels of $0.554 \mathrm{~m}$ length (L) and $0.146 \mathrm{~m}$ height $(\mathrm{H})$. Four various channel configurations are considered. In the first case, a smooth channel with no baffle is analyzed (see Figure 1a). In the second case, a flat rectangular baffled channel is investigated (see Figure 1b), and in the third case, S-shaped baffled channels are examined, i.e., Sbaffles pointed towards the upstream end: called S-upstream baffles (see Figure 1c); and S-baffles pointed towards the downstream end: called S-downstream baffled (see Figure 1d). Air, whose Prandtl number $(\operatorname{Pr})$ is 0.71 , is the working fluid used, and the Reynolds numbers considered range from 12,000 to 32,000 . The computational analysis of fluid dynamics and turbulent forcedconvection flow in the numerical domain is developed under the following conditions: (i) Steady two-dimensional fluid flow and thermal transfer, (ii) constant property incompressible Newtonian fluid, (iii) body forces and viscous dissipation are ignored, and (iv) the mode of radiation heat transfer is negligible.

\section{Governing Equations}

Based on the above condition, the mathematical model of the turbulent forced-convection airflow is governed by the Reynolds averaged Navier-Stokes (RANS) equations with the k-epsilon turbulence model [37] and the energy equation. In the Cartesian coordinate these equations can be written in the following compact form

$$
\frac{\partial}{\partial x}(\rho u \phi)+\frac{\partial}{\partial y}(\rho v \phi)=\frac{\partial}{\partial \mathrm{x}}\left[\Gamma_{\phi} \frac{\partial \phi}{\partial x}\right]+\frac{\partial}{\partial y}\left[\Gamma_{\phi} \frac{\partial \phi}{\partial y}\right]+S_{\phi}
$$

Where $\phi$ is a vector composed of the scalars $\mathrm{u}, \mathrm{v}, \mathrm{T}, \mathrm{k}$ and $\varepsilon$; $\mathrm{u}$ and $\mathrm{v}$ stand for the mean velocities towards the $\mathrm{x}$ and $\mathrm{y}$ axis respectively; $\mathrm{T}$ is the temperature; $\mathrm{k}$ and $\varepsilon$ stand for kinetic energy and turbulent dissipation rate, respectively; $\Gamma_{\phi}$ and $S_{\phi}$ represent the turbulent diffusion coefficient and 
the source term associated with the general variable $\phi$ in this order. The expressions of $\phi, \Gamma_{\phi}$ and $S_{\phi}$ are presented for:

Continuity equation

$$
\begin{gathered}
\phi=1 \\
\Gamma_{\phi}=0 \\
S_{\phi}=0
\end{gathered}
$$

Momentum equation in X-direction

$$
\begin{gathered}
\phi=u \\
\Gamma_{\phi}=\mu_{e} \\
S_{\phi}=-\frac{\partial p}{\partial x}+\frac{\partial}{\partial x}\left[\mu_{e}\left(\frac{\partial u}{\partial x}\right)\right]+\frac{\partial}{\partial y}\left[\mu_{e}\left(\frac{\partial v}{\partial x}\right)\right]
\end{gathered}
$$

Momentum equation in $Y$-direction

$$
\begin{gathered}
\phi=v \\
\Gamma_{\phi}=\mu_{e} \\
S_{\phi}=-\frac{\partial p}{\partial y}+\frac{\partial}{\partial x}\left[\mu_{e}\left(\frac{\partial u}{\partial y}\right)\right]+\frac{\partial}{\partial y}\left[\mu_{e}\left(\frac{\partial v}{\partial y}\right)\right]
\end{gathered}
$$

Energy equation

$$
\begin{gathered}
\phi=T \\
\Gamma_{\phi}=\frac{\mu_{e}}{\sigma_{T}} \\
S_{\phi}=0
\end{gathered}
$$

k-turbulent kinetic energy equation

$$
\begin{gathered}
\phi=\mathrm{k} \\
\Gamma_{\phi}=\mu_{\ell}+\frac{\mu_{t}}{\sigma_{k}} \\
S_{\phi}=-\rho \cdot \varepsilon+G
\end{gathered}
$$

E-turbulent dissipation rate equation

with

$$
\begin{gathered}
\phi=\varepsilon \\
\Gamma_{\phi}=\mu_{\ell}+\frac{\mu_{t}}{\sigma_{\varepsilon}} \\
S_{\phi}=\left(C_{1 \varepsilon} f_{1} G-C_{2 \varepsilon} f_{2} \rho \cdot \varepsilon\right) \frac{\varepsilon}{k}
\end{gathered}
$$

$$
G=\mu_{t}\left\{2 \cdot\left(\frac{\partial u}{\partial x}\right)^{2}+2 \cdot\left(\frac{\partial v}{\partial y}\right)^{2}+\left(\frac{\partial v}{\partial x}+\frac{\partial u}{\partial y}\right)^{2}\right\}
$$




$$
\begin{gathered}
\mu_{e}=\mu_{\ell}+\mu_{t} \\
\mu_{t}=f_{\mu} \rho \cdot C_{\mu} \frac{k^{2}}{\varepsilon}
\end{gathered}
$$

Where $\mathrm{C}_{1 \varepsilon}=\mathrm{C}_{3 \varepsilon}=1.44, \mathrm{C}_{2 \varepsilon}=1.92, \mathrm{C}_{\mu}=0.09, \sigma_{\mathrm{k}}=1.0, \sigma_{\varepsilon}=1.3$, and $\sigma_{\mathrm{T}}=0.85$ are the turbulent constants of the model [37].

\section{Limit Conditions}

A uniform one-dimensional velocity profile $\left(u=U_{\text {in }}\right)$ is introduced at the intake of the channel $(x=$ $0)$ while an atmospheric pressure-outlet condition is applied at the exit $(x=L)$ [21]. No-slip and impermeability boundary conditions are applied over the solid boundaries [21]. A condition of the constant surface temperature of $102^{\circ} \mathrm{C}\left(\mathrm{T}_{\mathrm{w}}=375 \mathrm{~K}\right)$ was applied on the upper and lower walls of the channel [38]. The temperature of air was set equal to $27^{\circ} \mathrm{C}\left(\mathrm{T}_{\text {in }}=300 \mathrm{~K}\right)$ at the inlet of the channel [38]. These boundary conditions are presented as At the intake of the computational domain $(x=0)$

$$
\begin{gathered}
u=U_{i n} \\
v=0 \\
T=T_{i n} \\
\mathrm{k}_{\mathrm{in}}=0.005 U_{\text {in }}^{2} \\
\varepsilon_{\text {in }}=0.1 k_{\text {in }}^{2}
\end{gathered}
$$

At the channel walls (upper wall: $y=H / 2$; lower wall: $y=-H / 2$ )

$$
\begin{gathered}
u=v=0 \\
k=\varepsilon=0 \\
T=T_{W}
\end{gathered}
$$

At the fluid/solid interface

$$
\begin{gathered}
T_{f}=T_{s} \\
\lambda_{f} \frac{\partial T_{f}}{\partial n}=\lambda_{s} \frac{\partial T_{s}}{\partial n}
\end{gathered}
$$

Where $n$ is the normal coordinate to the wall.

At the exit $(x=L)$

$$
\begin{gathered}
\frac{\partial u}{\partial x}=\frac{\partial v}{\partial x}=\frac{\partial T}{\partial x}=\frac{\partial k}{\partial x}=\frac{\partial \varepsilon}{\partial x}=0 \\
P=P_{a t m}
\end{gathered}
$$

The flow Reynolds number (Re) based on channel aeraulic diameter,

$$
D_{h}=2 H W /(H+W)
$$

is given by

$$
\operatorname{Re}=\rho \bar{U} D_{h} / \mu
$$


The skin friction coefficient (Cf) is given by

$$
C f=\frac{\tau_{w}}{\frac{1}{2} \rho \bar{U}^{2}}
$$

The friction factor $(\mathrm{f})$ is evaluated from the pressure drop $(\Delta \mathrm{P})$ as

$$
f=\frac{(\Delta P / L) D_{h}}{\frac{1}{2} \rho \bar{U}^{2}}
$$

where $\bar{U}$ presents the average axial velocity of the section, and $\tau_{w}$ is the shear stress to the wall. For determining the heat transfer rate inside the channel, the heat transfer is measured by the local Nusselt number $\left(\mathrm{Nu}_{\mathrm{x}}\right)$ which can be written as

$$
N u_{x}=\frac{h_{x} D_{h}}{k_{f}}
$$

and the average Nusselt number $(\mathrm{Nu})$ can be obtained by

$$
N u=\frac{1}{L} \int N u_{x} \partial x
$$

The following expression represents the thermal enhancement factor (TEF)

$$
T E F=\left(N u / N u_{0}\right) /\left(f / f_{0}\right)^{1 / 3}
$$

The Dittus-Boelter [39] and Petukhov [40] correlations can be used to normalize the average Nusselt number and friction factor, respectively. The quantities $\mathrm{Nu}_{0}$ and $\mathrm{f}_{0}$ are the average Nusselt number and the friction factor of the smooth channel, respectively. The Dittus and Boelter correlation has the form:

$$
N u_{0}=0.023 \operatorname{Re}^{0.8} \operatorname{Pr}^{0.4} \text { for } \operatorname{Re} \geq 10^{4}
$$

The Petukhov correlation has the form:

$$
f_{0}=(0.79 \ln \operatorname{Re}-1.64)^{-2} \text { for } 3 \times 10^{3} \leq \operatorname{Re} \leq 5 \times 10^{6}
$$

\section{CFD TECHNIQUE}

\section{Numerical Solution}

Commercial CFD software FLUENT is used to simulate the incompressible steady fluid flow and heat transfer in the computational model. The governing flow equations are integrated by the Finite Volume Method (FVM), details of which can be found in Patankar [41]. The QUICK numerical scheme, developed by Leonard and Mokhtari [42], is employed to discretize the convective terms. The SIMPLE discretization algorithm is used for pressure velocity. 


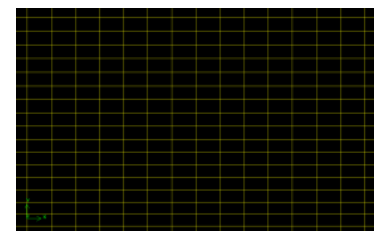

Detail A

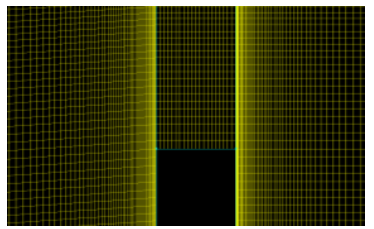

Detail B

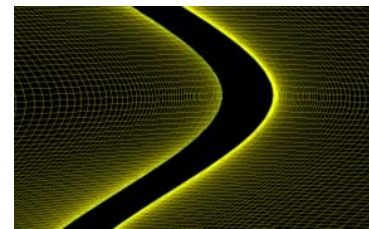

Detail C

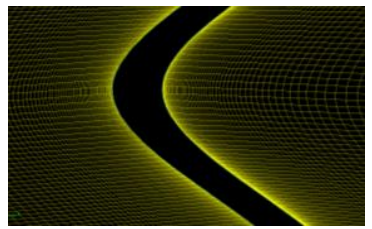

Detail D

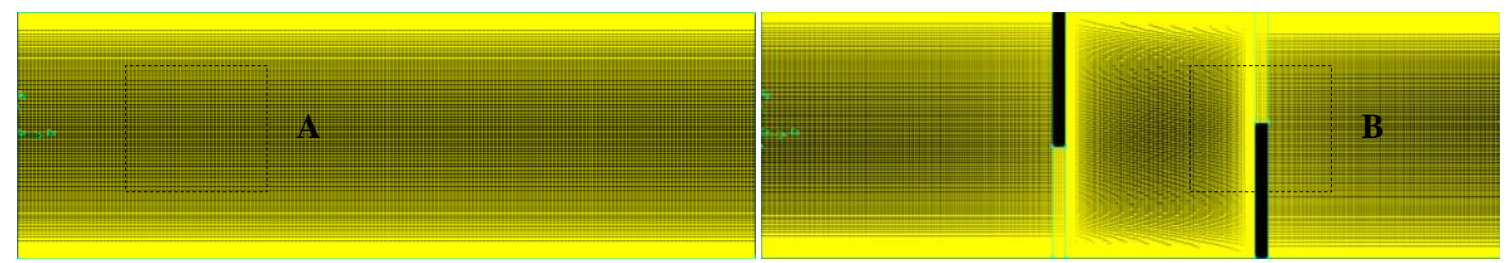

(a)

(b)

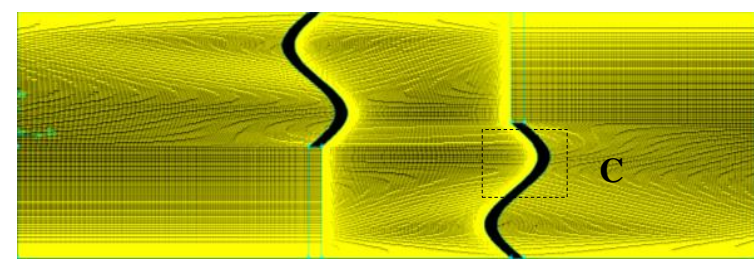

(c)

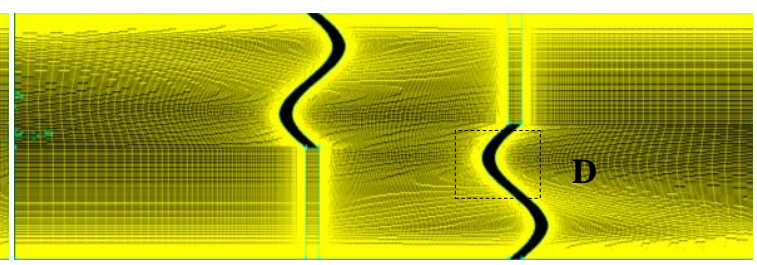

(d)

Figure 2. Structured mesh of the quadrilateral type for the geometric model of the current analysis: (a) smooth channel with no baffle, (b) flat baffled channel, (c) S-upstream baffled channel, and (d) S-downstream baffled channel.

\section{Numerical Mesh}

A quadrilateral-type structured grid in the two-directions was inserted (see Figure 2). The grid independence tests were performed by realizing CFD simulations in the whole domain investigated, using different grid systems with the number of mesh nodes ranging from 35 to 145 along the pipe depth and 95 to 370 along the length. The grid system with the number of nodes equal to $245 \times 95$ (in $\mathrm{X}$ and $\mathrm{Y}$ directions respectively) performs around $0.330 \%$, and $0.372 \%$ deviation for the $\mathrm{Nu}$, and $f$, respectively, in compared with the grid of size $370 \times 145$. Therefore, the grid cell of $245 \times 95$ is selected for the rest of our study. The solution was assumed to be converged when the following criterion was satisfied as

$$
\operatorname{Max}\left(\frac{\left|\phi-\phi^{*}\right|}{\left|\phi^{*}\right|}\right) \leq \delta
$$

Where * denote the previews iteration value, and $\delta$ is a prescribed error. For the present simulation, we select $\delta=10^{-9}$ for $\phi \equiv(\mathrm{u}, \mathrm{v}, \mathrm{k}, \varepsilon)$ and $\delta=10^{-12}$ for $\phi \equiv(\mathrm{T})$.

\section{Numerical Validation}

For a rectangular air channel with simple flat rectangular obstacles, the distributions of the axial profiles of speed and pressure coefficient along the depth of the channel are followed and shown in Figure 3 (a) and (b), respectively. 


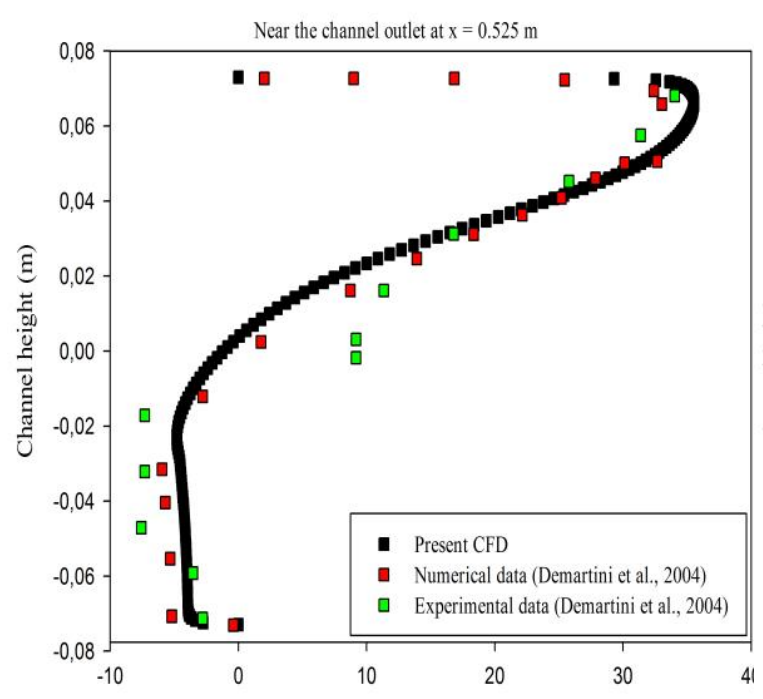

(a)

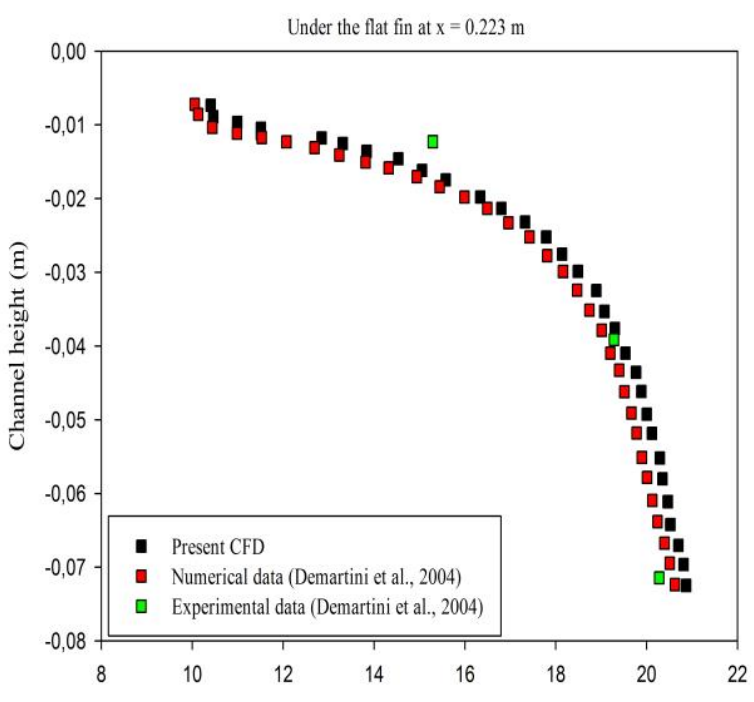

(b)

Pressure coefficient

Figure 3. Numerical validation of (a) axial velocity and (b) pressure coefficient for $\operatorname{Re}=8.73 \times 104$.

The numerical results were validated with the numerical and experimental results of Demartini et al. [21] for the same structural condition under similar operating parameters. As shown on these plots, a good agreement is obtained.

\section{Smooth Channel Verification}

The evolutions of the Nusselt number and friction factor as a function of the Reynolds number are also simulated for a smooth air channel and compared with empirical correlation of Dittus-Boelter and Petukhov, as shown in Figure 4 (a) and (b), respectively. As can be shown in Figure 4, the present smooth channel results agree well with the available correlations with $+3.5 \%$ in comparison to Dittus-Boelter correlation [39] for the $\mathrm{Nu}_{0}$, and $-1.15 \%$ in comparison to Petukhov correlation [40]

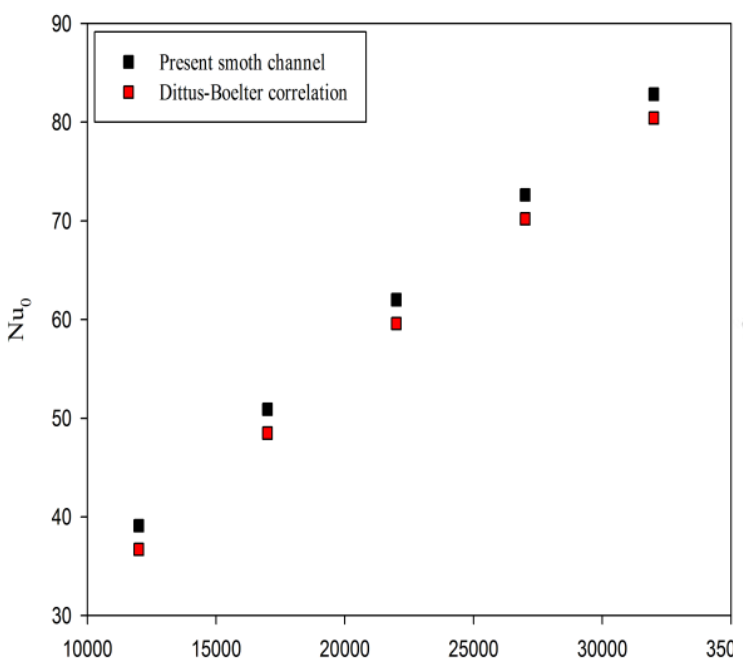

(a)

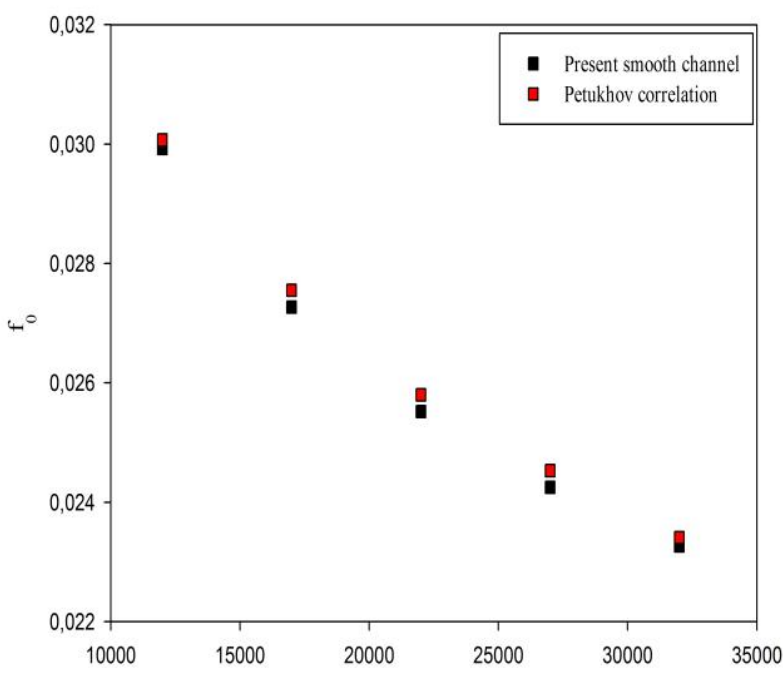

(b)
$\mathrm{Re}$

Figure 4. Numerical verification of (a) Nusselt number and (b) friction factor for smooth channel with no baffle. 

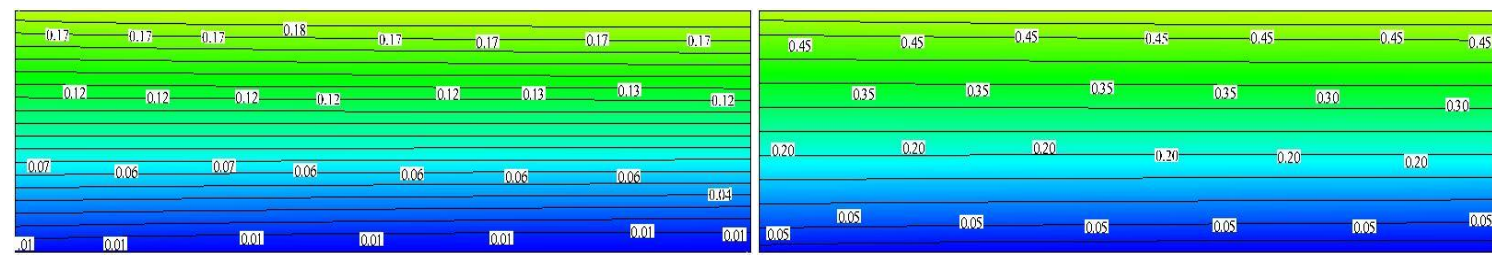

(a)
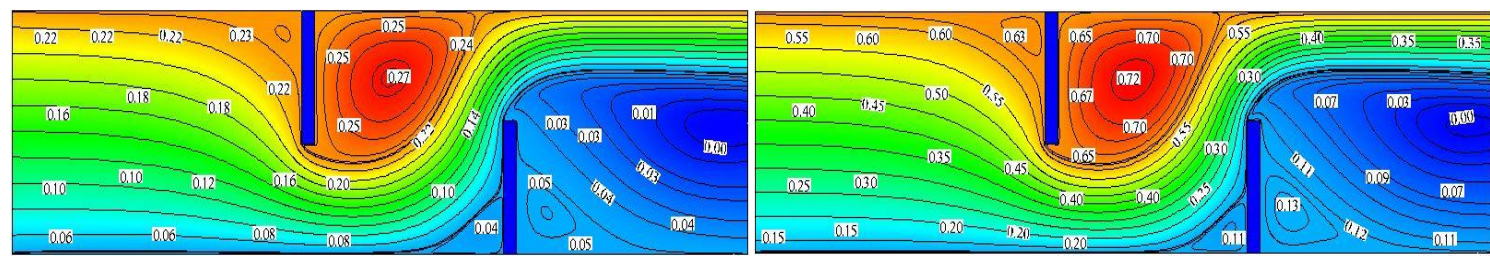

(b)
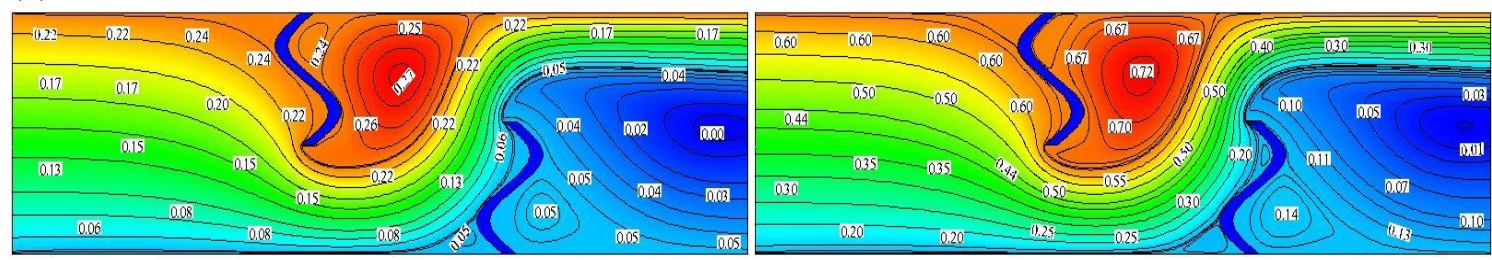

(c)
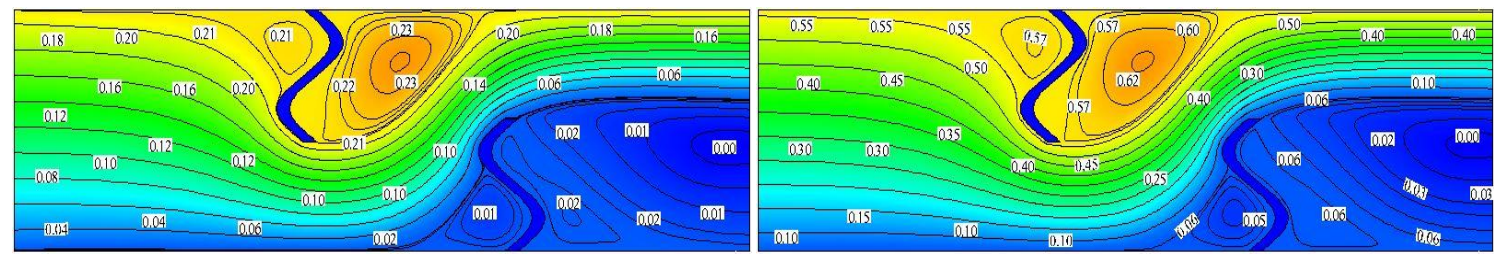

(d)

$$
\operatorname{Re}=12,000
$$

$\operatorname{Re}=32,000$

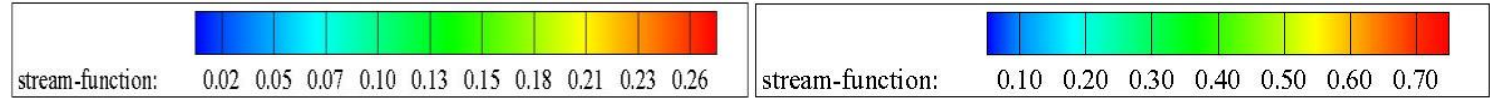

Figure 5. Streamlines as a function of Re for: (a) smooth channel, (b) flat baffled channel, (c) Supstream baffled channel, and (d) S-downstream baffled channel.

\section{RESULTS AND DISCUSSION}

\section{Stream Functions}

The plots in Figure 5 show the contours of streamlines for different channel models, i.e., smooth channel with no baffle (see Figure 5a), channel with upper and lower wall-mounted flat rectangularshaped baffles (see Figure 5b), channel with S-upstream shaped baffles (see Figure 5c), and channel with S-downstream shaped baffles (see Figure 5d), at various $\operatorname{Re}$ values, i.e., $\operatorname{Re}=12,000$ and $\operatorname{Re}=$ 32,000 . In the smooth channel case, the streamlines are uniform along the channel length. In baffled channel cases, the plots reveal the existence of three main regions. In the first region, just upstream of the baffles, the fluid is accelerated and arrives with an axial speed. At the approach of the baffles, the current lines are deflected. In the second region, located between the top of each baffle and the walls of the channel, the flow is accelerated due to the effect of cross-sectional reduction. In the third region, downstream of the baffles, the current lines are generated by the effect of flow expansion, thus leaving the section formed by the baffles and the walls. 


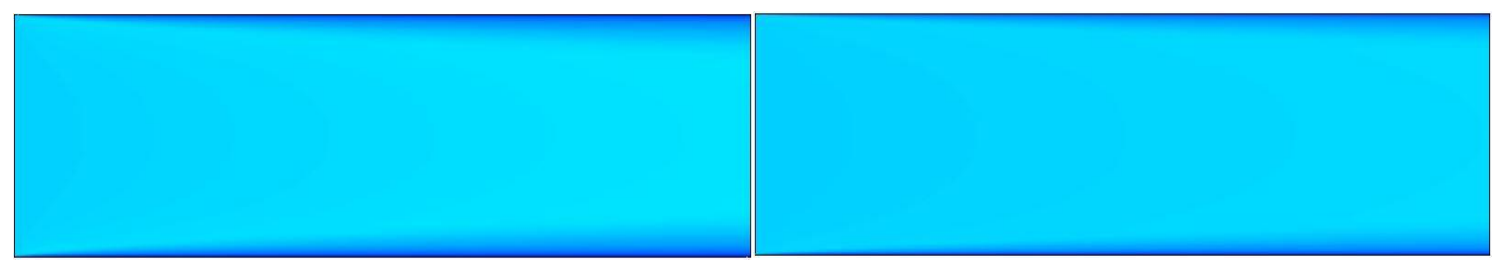

(a)

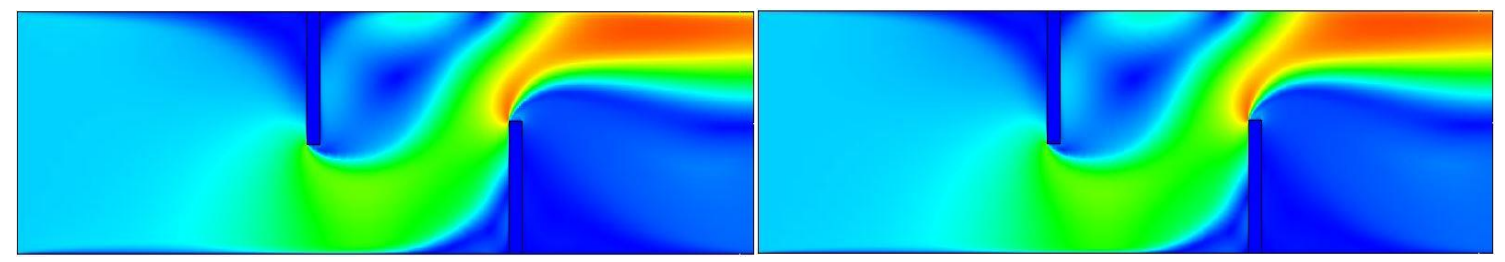

(b)

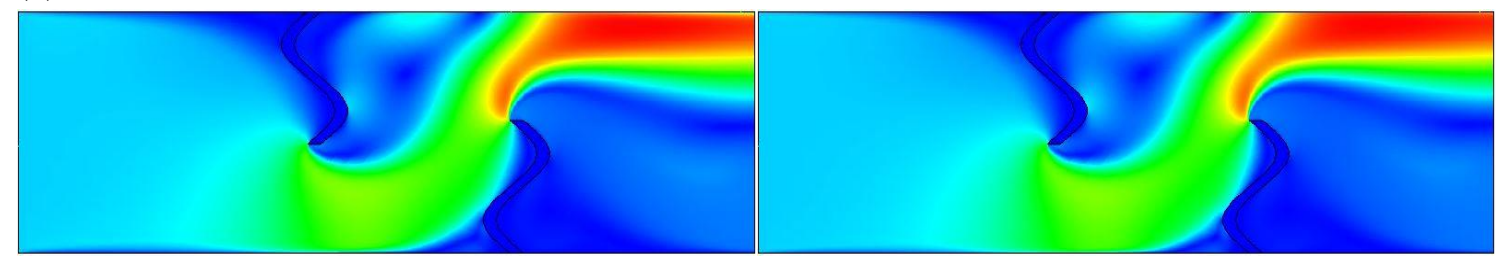

(c)
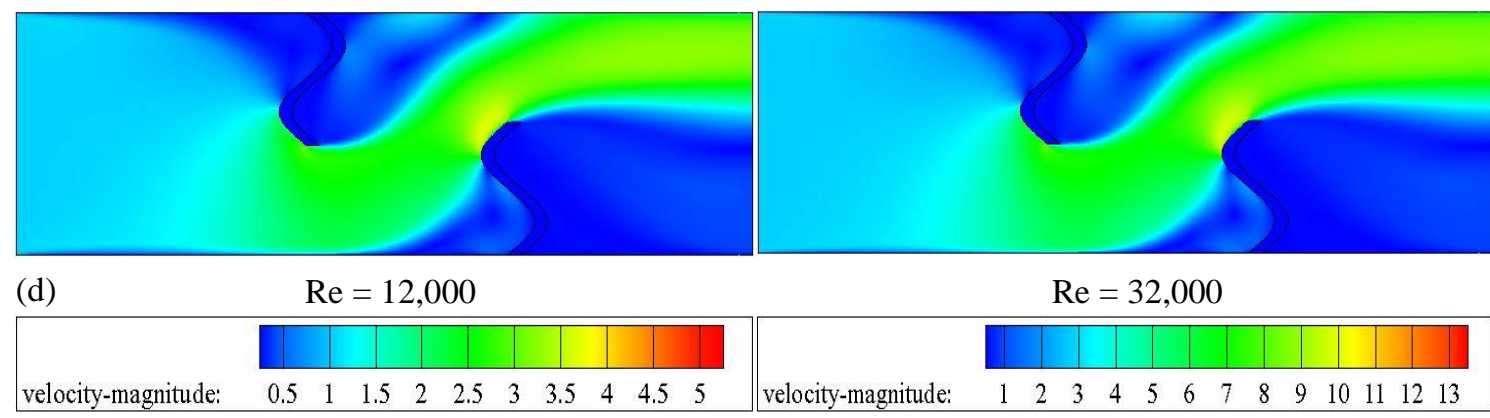

Figure 6. Velocity-magnitude as a function of Re for: (a) smooth channel, (b) flat baffled channel, (c) S-upstream baffled channel, and (d) S-downstream baffled channel.

The most important phenomenon occurring in this zone is the formation of a recirculating flow whose extent is proportional to the Reynolds number from 12,000 to 32,000. For both investigated Re number cases, the baffle in the S-downstream type gives the lowest stream-function value and one in S-upstream type yields slightly better than the rectangular baffle. The S-upstream baffle provides higher stream-function value than the S-downstream around $14.720 \%$ for $\mathrm{Re}=32,000$.

\section{Mean Velocity}

The effect of the channel configuration (i.e., plain channel without baffles, simple baffled channel, and channels with S-upstream and/or S-downstream baffles) on the near wall flow structure in terms of mean velocity is reported in Figure 6. Both the cases of the Reynolds number $(12,000$ and $32,000)$ are also reported. As shown in the figure and along the smooth channel section, the mean velocity profiles are uniform for both the Re number cases used (see Figure 6a). For using the obstacles, it can clearly be noticed that the values of the fluid velocity are very low in the vicinity of the two baffles, especially in the downstream regions; this is due to the presence of the recirculation zones (see Figures 5 and 6 a-c). 


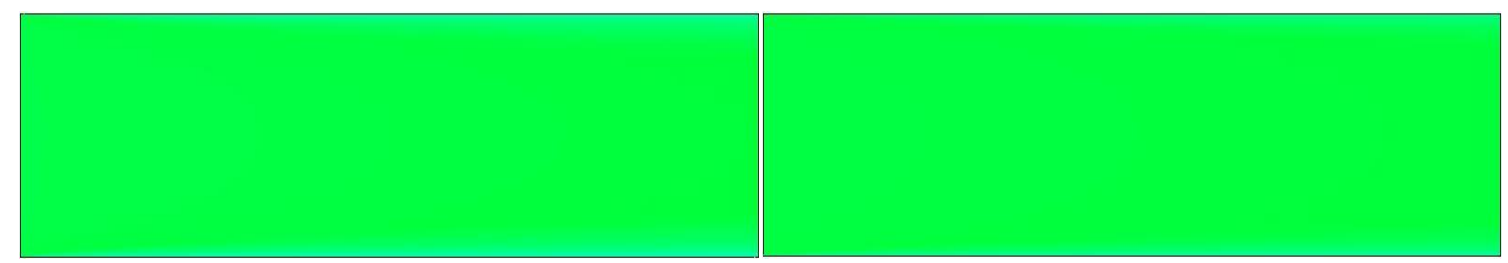

(a)

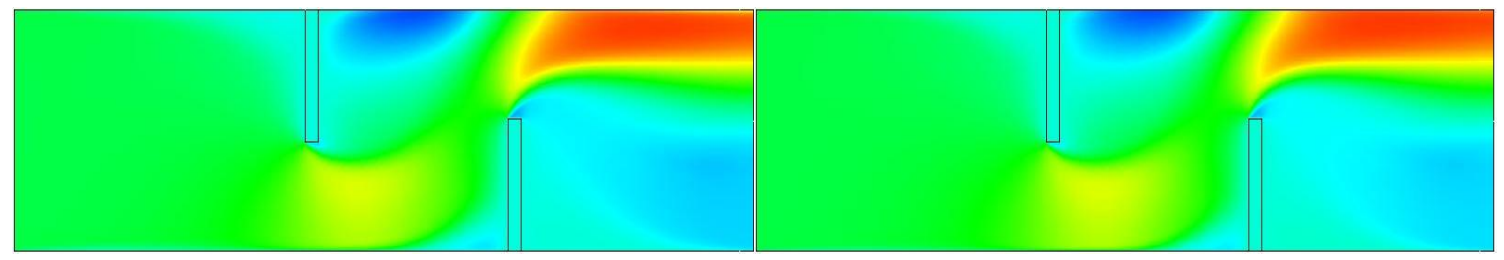

(b)

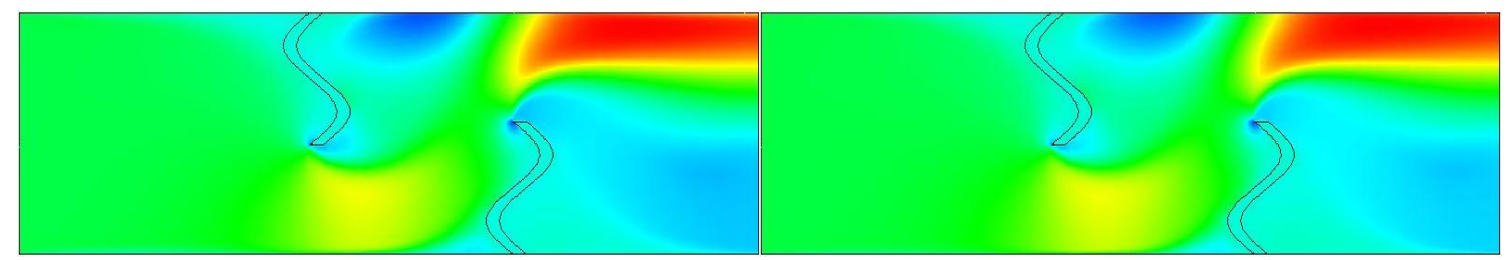

(c)
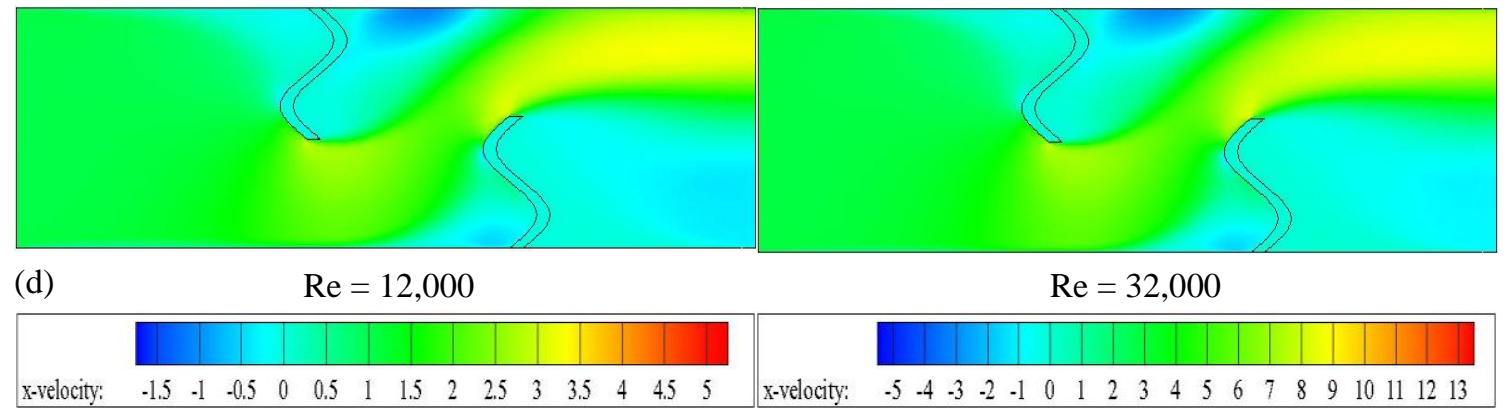

Figure 7. Axial velocity as a function of Re for: (a) smooth channel, (b) flat baffled channel, (c) Supstream baffled channel, and (d) S-downstream baffled channel.

Far from these zones, the current lines become parallel, which results in the progressive development of the flow. One should also note that the velocity increases in the space between the end of each baffle and the wall of the channel. This rise in velocity is generated first by the presence of the baffle and then by the presence of a recycling which results in a sudden change in the direction of the flow. It is also observed that the highest values of the velocity appear near the top of the channel, with an acceleration process that begins just after the second baffle. From the figure, it can clearly be seen that the velocity is proportional to the Reynolds number, for all cases investigated. In a comparison with the simple baffled channel, the mean velocity augments in the case of S-upstream baffles by $8.359 \%$ at $\mathrm{Re}=32,000$. However, the mean velocity decreases by $22.258 \%$ when the baffle form is S-downstream at the same upper Reynolds number, $\operatorname{Re}=32,000$.

\section{X-Velocity}

The contour plots of axial velocity are displayed in Figure 7 (a-d) for different channel models, i.e., smooth channel with no obstacle, channel with simple baffles, channel with S-upstream baffles, and channel with S-downstream baffles, respectively. In the figure, the axial velocity is related as a function of Reynolds number $(\operatorname{Re}=12,000$ and $\operatorname{Re}=32,000)$. The introduction of the obstacles leads to extremely considerable augmentation in the axial velocity in comparison with the smooth channel with no obstacles. Note that the presence of the first baffle in the upper half of the channel induces a strong decrease in the axial velocity. Negative velocities indicate the presence of a small 
recirculation zone located upstream of this same baffle, paradoxically in the lower half, where the flow increases, and particularly in the vicinity of the passage under the baffle. Downstream of this same first baffle, two large distinct zones can be quantified, as presented in Figure 7. The first one is an area where the fluid particles follow the main flow direction. The recirculation zone is located in the second region in the vicinity of the upper right baffle face. The flow is reversed and this causes the flow to peel off at the top wall of the channel; the velocity profiles are directed in the way opposite to that of the flow. Upstream of the second baffle, note that the flow velocity, when approaching the baffle, is reduced in the lower part of the canal, whereas in the upper part the flow begins to accelerate towards this breach above the second baffle. This limitation depends substantially on the recirculation zones, which are characterized by negative values and are located upstream and downstream of the second baffle. Vortices occur in the vicinity of these zones; they develop and increase very strongly the resistance to the flow. These disordered but localized movements are characterized by negative values, as shown in Figure 7. Downstream and according to results in Figure 7, the speed value reaches approximately $13.850 \mathrm{~m} / \mathrm{s}$, which is 4.948 times greater than the velocity at the inlet for the highest value of the Re number. These values can be reached only because of the very high recirculation to the rear of the second obstacle. The increase in the Reynolds number leads to an acceleration of the flow and causes a rise in the fluid x-velocity, indicating that the length of the vortices is proportional to the augmentation in the Re number, which characterizes the flow, as confirmed in Figure 5. It is clear that changing the baffle shape has a more reasonable impact on the upper left side of the baffle; this is due to the deviation of the flow direction. The S-downstream shaped baffles showed decreases of about $31.708 \%$ in axial velocity value relative to that in the simple flat rectangular baffle. However, the value of axial velocity augments by $7.714 \%$ when the baffle type is S-upstream shape.

\section{Y-Velocity}

As for the transverse component of the velocity, it is interesting to note that negative velocity gradients are observed at the top of the upper wall-mounted baffle and positive velocity gradients at the top of the lower wall-mounted baffle, Figure 8. In the figure, the y-velocity values are also related as a function of Reynolds number. It is seen that the y-velocity augments with augmenting Reynolds number in all cases and in general, the maximum y-velocity is obtained for the simple baffle while the lowest one is for the S-downstream baffle. At the upper value in the Reynolds number, the smooth channel seemed to decrease the transverse velocity by about $99.548 \%$ relative to the flat rectangular-shaped baffled channel (channel with simple baffles). For the S-shaped baffles, the decrease in the y-velocity relative to that for the simple baffle was about $3.856 \%$ for Supstream, and $26.878 \%$ for S-downstream. 


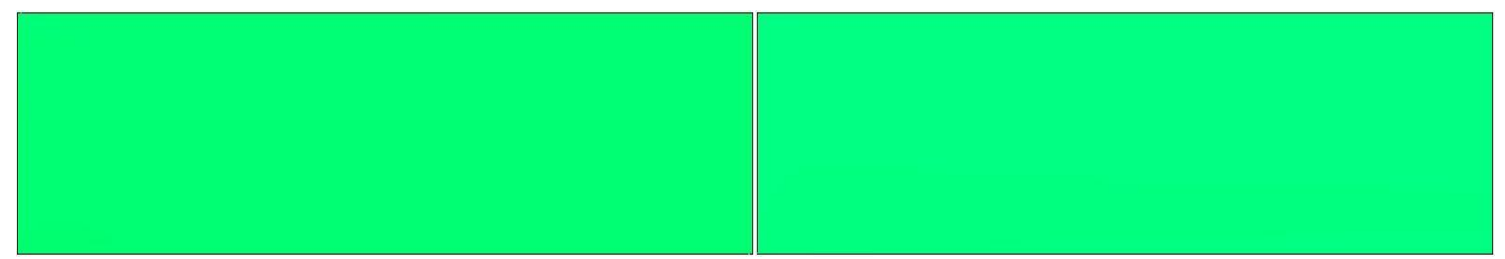

(a)

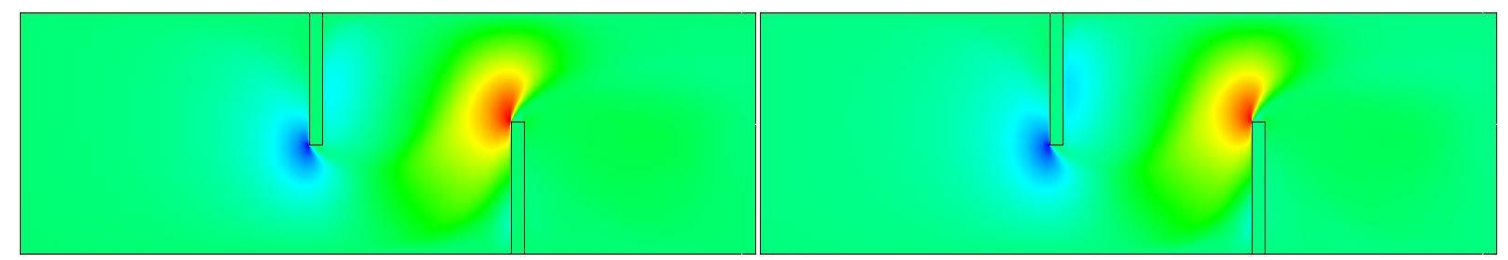

(b)

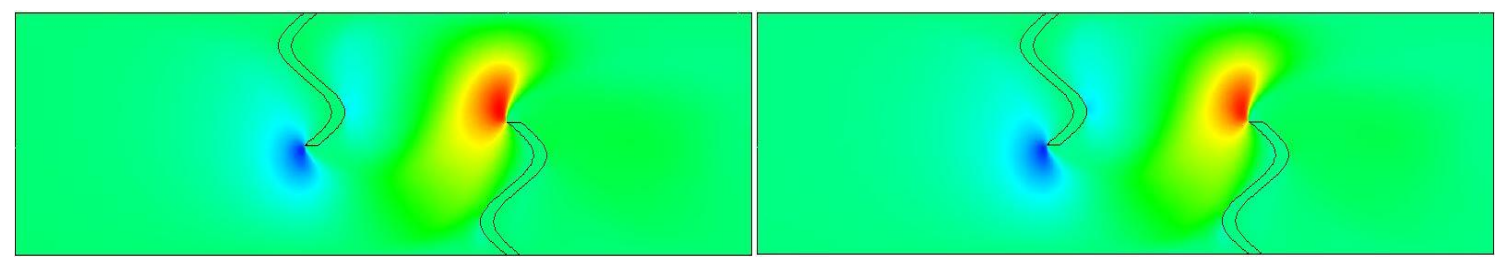

(c)

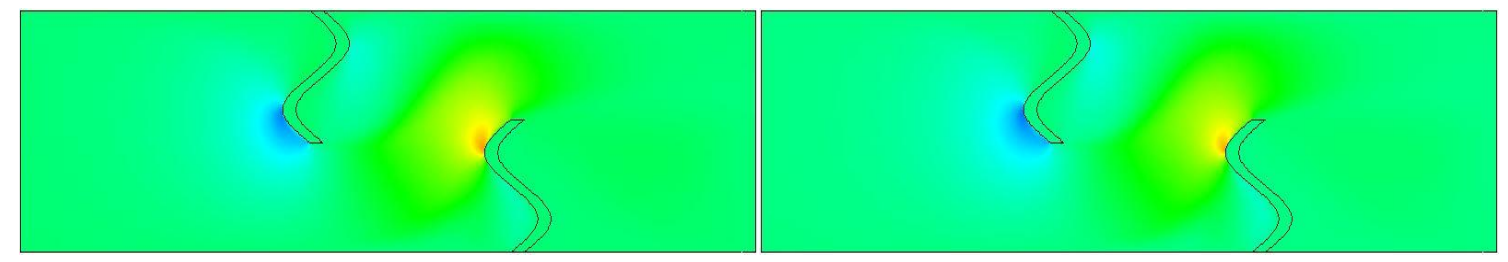

(d)

$\operatorname{Re}=12,000$

$\operatorname{Re}=32,000$

\begin{tabular}{|l|lllllllllllll|}
\hline & & & & & & & & & & & & & \\
y-velocity: & -2 & -1.5 & -1 & -0.5 & 0 & 0.5 & 1 & 1.5 & 2 & 2.5 & 3 & 3.5 & 4 \\
\hline
\end{tabular}

Figure 8. Transverse velocity as a function of Re for: (a) smooth channel, (b) flat baffled channel, (c) S-upstream baffled channel, and (d) S-downstream baffled channel.

\section{Coefficient of Dynamic Pressure}

To follow more precisely the evolution of fluid flow into the airway, we added the contour plots of dynamic pressure fields as listed below in Figure 9 (a)-(d). As illustrated in this figure and similar to the results in Figure 6 (a)-(d) of the speed fields, the pressure values are very low next to the baffles, especially in the back areas, because of the existence of recirculation cells. In areas confined between the upper sides of the baffles and the inner walls of the channel, the pressure values increase. The coefficients of dynamic pressure are maximal next to the upper surface of the airway near the exit, also near the top left side of the lower wall-mounted baffle, due to the high speed of air flow in these regions. These same plots also indicate that the dynamic pressure coefficients, for all channel models, increase significantly as the number of Reynolds number. The pressure values range from $8.436 \mathrm{~Pa}$ as the lowest value in the case of the $\mathrm{S}$-downstream baffle, and $117.508 \mathrm{~Pa}$ as the maximum value in the case of a baffle of S-upstream form. Moreover, the pressure value in the case of a simple flat rectangular baffle is equal to 100.076 Pa. This value varies according to the geometry of the baffle shape so that we record a decrease in the dynamic pressure values for the case of S-downstream baffles by $39.561 \%$ at the upper value of Re number, while we record an increase in the dynamic coefficient of pressure in the case of S-upstream baffles $17.418 \%$, at the same upper Re number. 


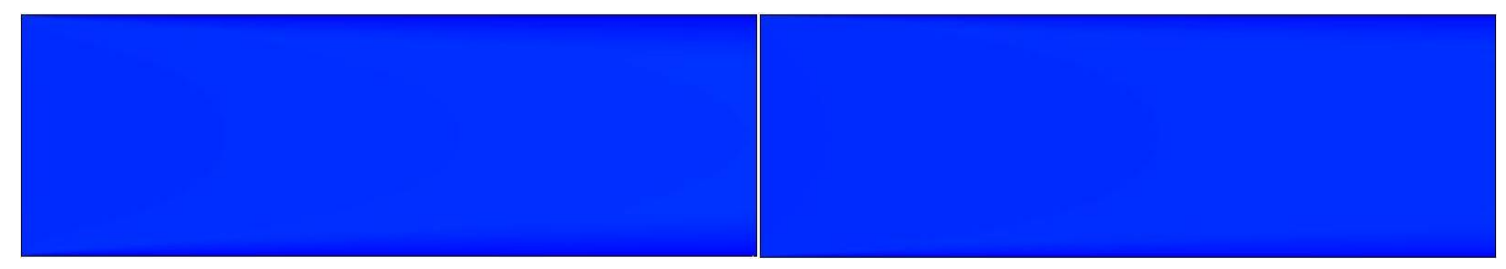

(a)

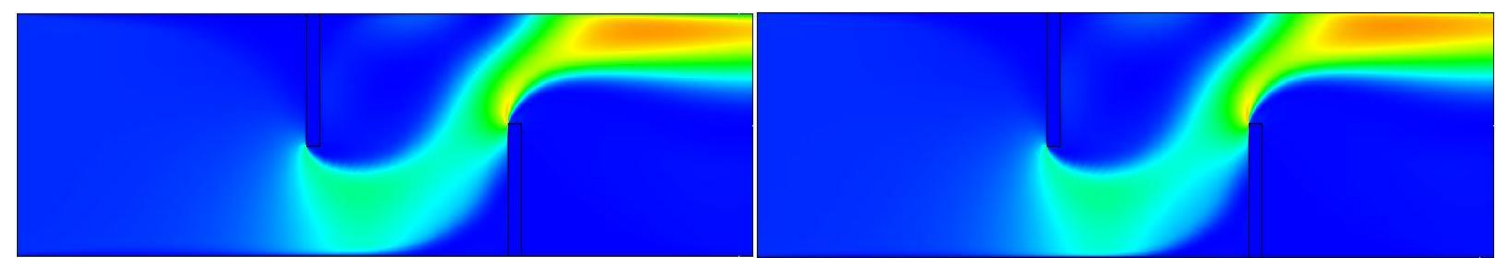

(b)

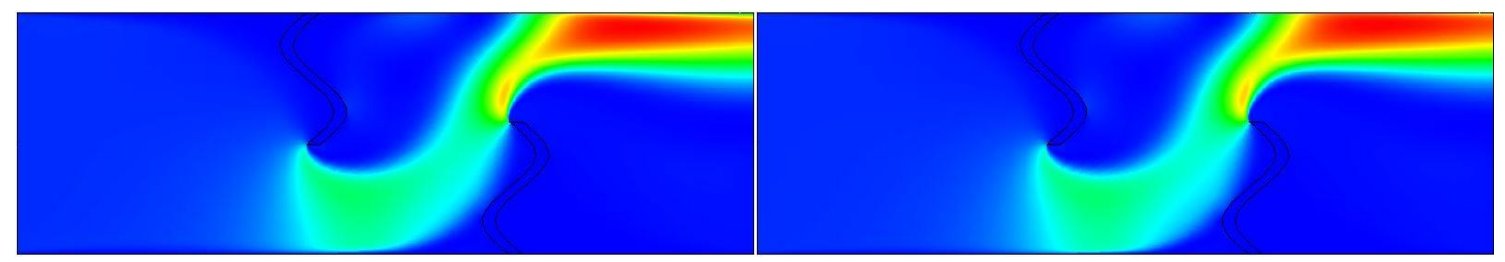

(c)
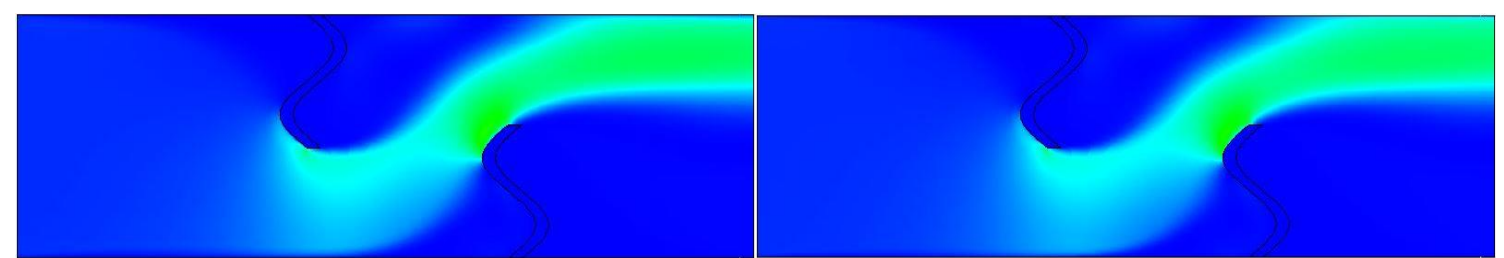

(d)

$\operatorname{Re}=32,000$

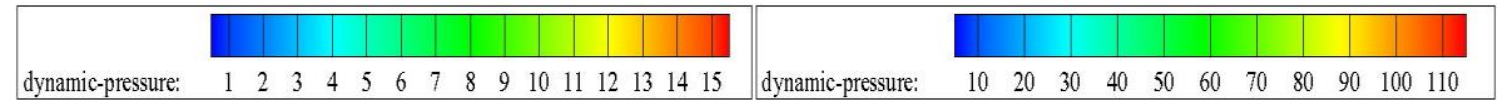

Figure 9. Dynamic pressure as a function of Re for: (a) smooth channel, (b) flat baffled channel, (c) S-upstream baffled channel, and (d) S-downstream baffled channel.

As expected, the S-upstream baffle has the largest value of pressure as compared to other baffles, with an increase of $14.834 \%$ and $48.527 \%$ in the cases corresponding to rectangular and Sdownstream baffles, respectively, at the same Reynolds number value, $\operatorname{Re}=32,000$. The pressure for the simple, S-upstream and S-downstream baffle cases is $94.634 \mathrm{~Pa}, 112.066 \mathrm{~Pa}$, and $55.042 \mathrm{~Pa}$ higher than the no baffle case (smooth channel with no obstacles), respectively.

\section{Kinetic Energy of Turbulence}

The contour plots of turbulence kinetic energy (TKE) fields are shown in Figure 10 (a)-(d) for various channel geometries. In the plots, the TKE values are related as a function of Re number. In all baffled channel cases, the baffled channel airflows give upper values of TKE than that for no obstacle case due to the creation of high vortices in the baffled channel, leading to higher TKE values. The trends of turbulent kinetic energy are similar for all obstacle cases under investigation. The plots show the largest value in the region opposite the right baffle and the smallest value in the region around the left baffle for both the Re numbers simulated. 

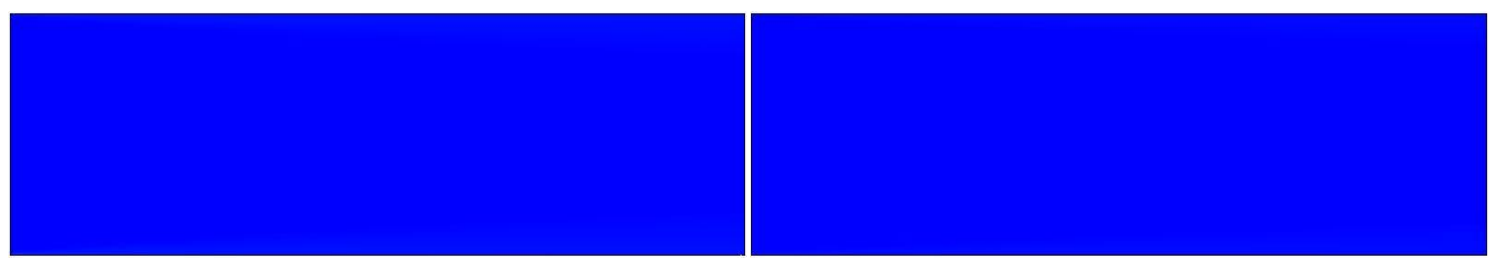

(a)
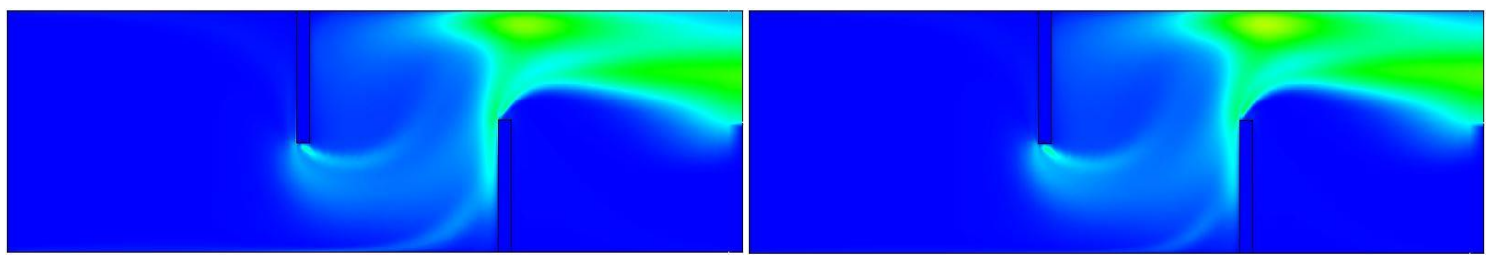

(b)
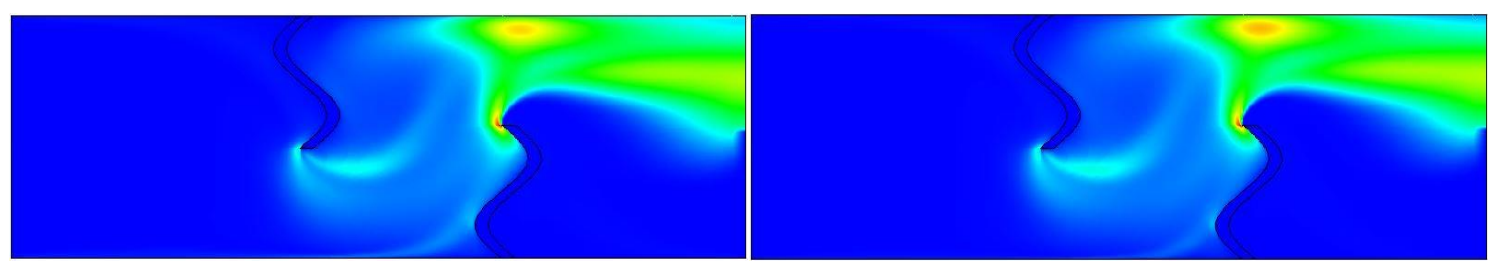

(c)
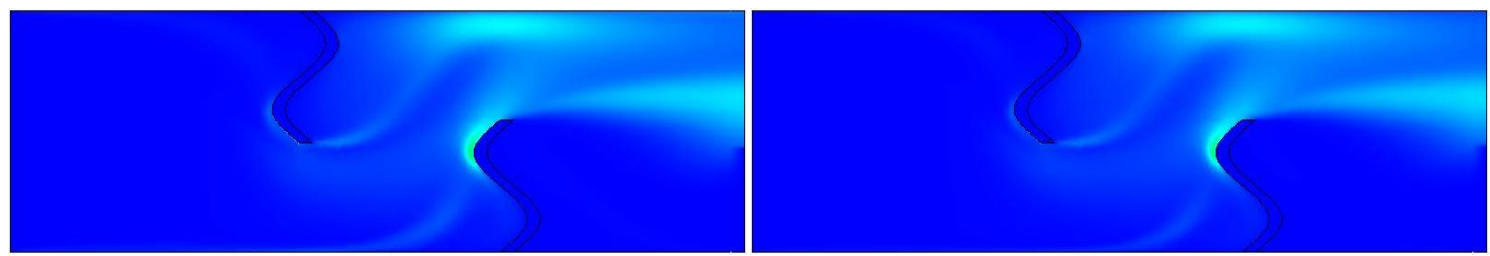

(d)

$\operatorname{Re}=12,000$

$\operatorname{Re}=32,000$

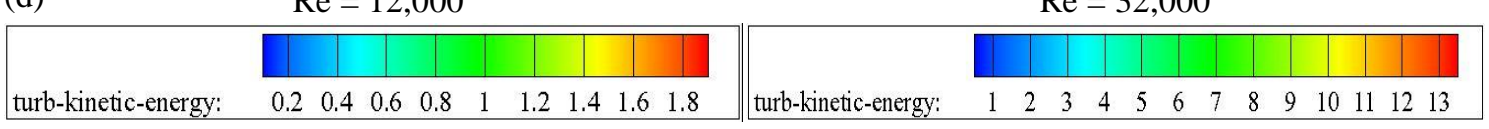

Figure 10. TKE as a function of Re for: (a) smooth channel, (b) flat baffled channel, (c) S-upstream baffled channel, and (d) S-downstream baffled channel.

The turbulent kinetic energy augments with the augmentation of the Reynolds number $(\mathrm{Re})$ and consequently, the $\mathrm{Re}=32,000$ provides maximum turbulent kinetic energy in all cases studied. The use of S-upstream baffle shows better turbulent kinetic energy distribution values over the $S$ downstream baffle at almost stations. In a comparison with the flat rectangular baffle case, the TKE value decreases in the case of S-downstream baffle by $38.618 \%$ at $\mathrm{Re}=32,000$. However, the TKE value increases by $47.275 \%$ when the baffle geometry is S-upstream at the same upper Reynolds number.

\section{Viscosity-Turbulent}

The impact of the baffles on the turbulent viscosity across the tested ducts is shown in Figure 11 (a) to (d). Similarly, to the results in Figure 10 (a) to (d), the largest variations in the turbulent viscosity are found in the regions opposite the lower wall-attached baffle, due to the high velocities in those regions. In addition, it is interesting to note that the value of the turbulent viscosity tends to augments with the rise of Reynolds number values for the three simple, S-upstream and Sdownstream models of the baffle. However, it is worth noting that for all Reynolds numbers employed the model of S-upstream provides the highest turbulent viscosity value. 

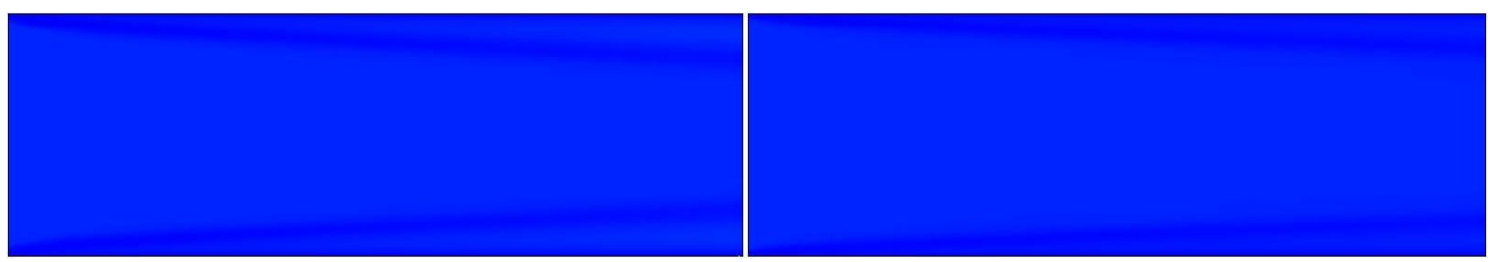

(a)
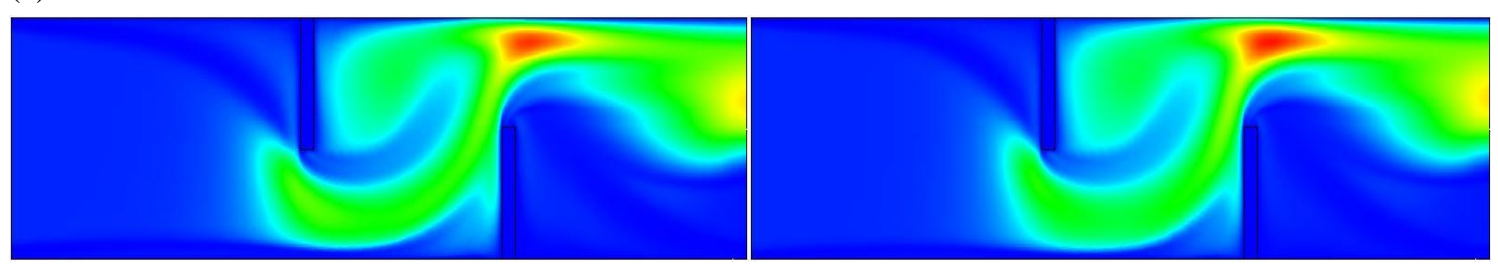

(b)

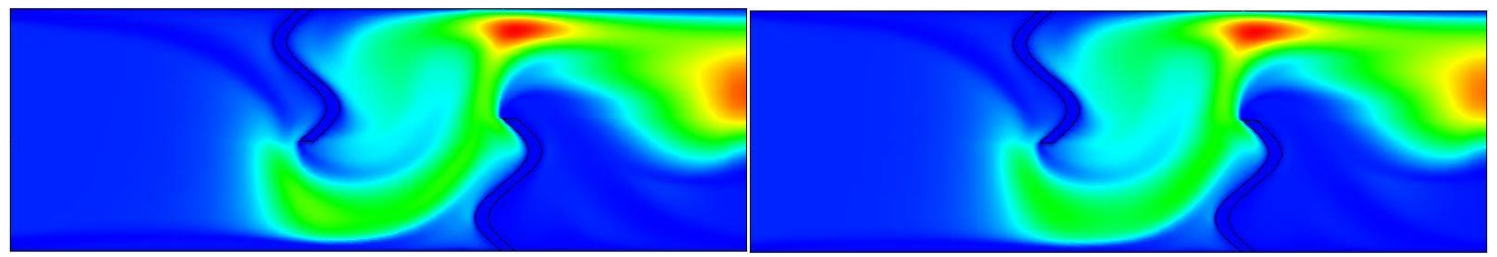

(c)
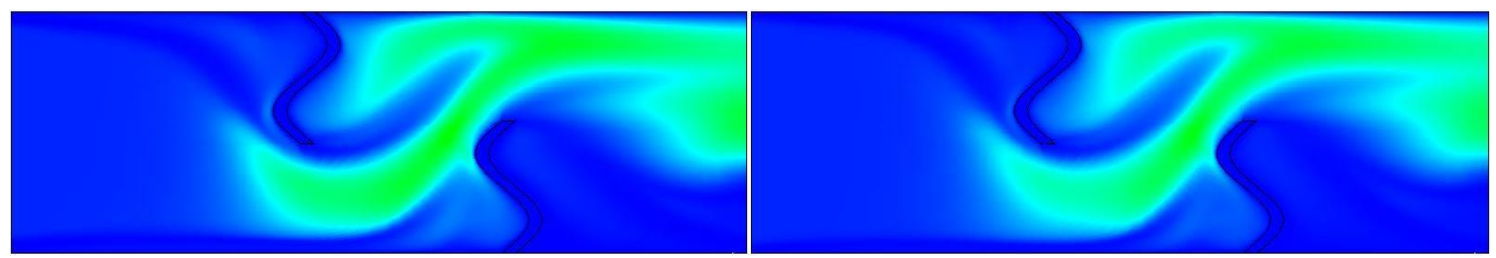

(d)

$\operatorname{Re}=12,000$

$\operatorname{Re}=32,000$

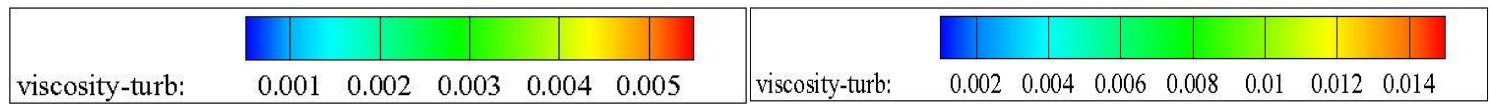

Figure 11. Turbulent viscosity as a function of Re for: (a) smooth channel, (b) flat baffled channel, (c) S-upstream baffled channel, and (d) S-downstream baffled channel.

In addition, the use of S-upstream model baffle results in higher turbulent viscosity than the use of simple, and S-downstream baffles up to $1.928 \%$, and $51.733 \%$, respectively. The data analysis also shows that the maximum turbulent viscosity for the obstacle form of simple, S-upstream, and Sdownstream is approximately $28.537,29.098$, and 14.044 times upper than that for the no baffle case.

\section{Intensity of Turbulence}

Figure 12 shows the plots of the turbulent intensity fields. The airflow was simulated for the Reynolds number of 12,000 and 32,000. In Figure 12, the turbulent intensity tends to augmentation with the increase of the Reynolds number for the all cases simulated. 


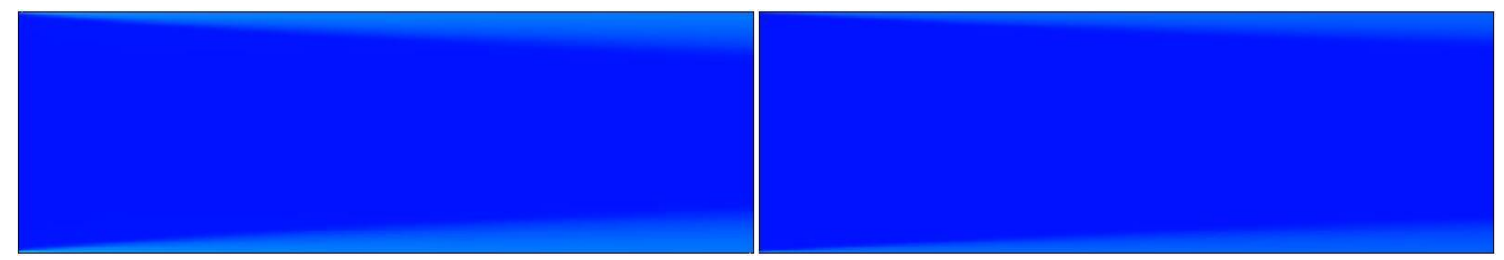

(a)

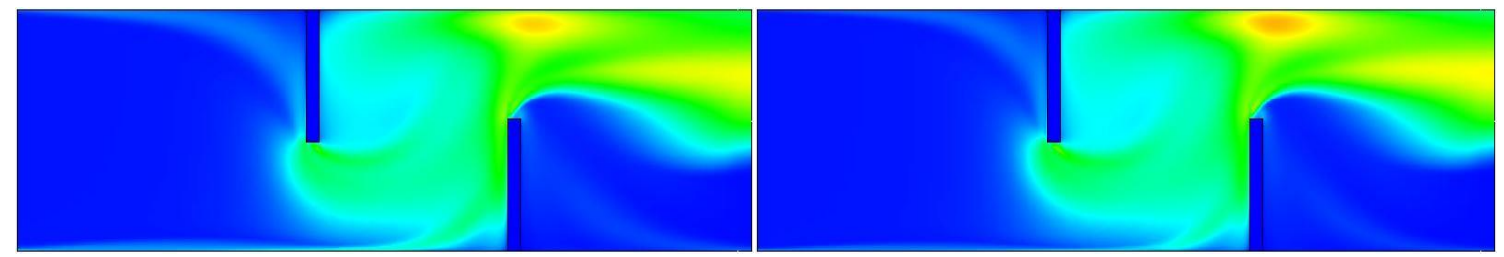

(b)
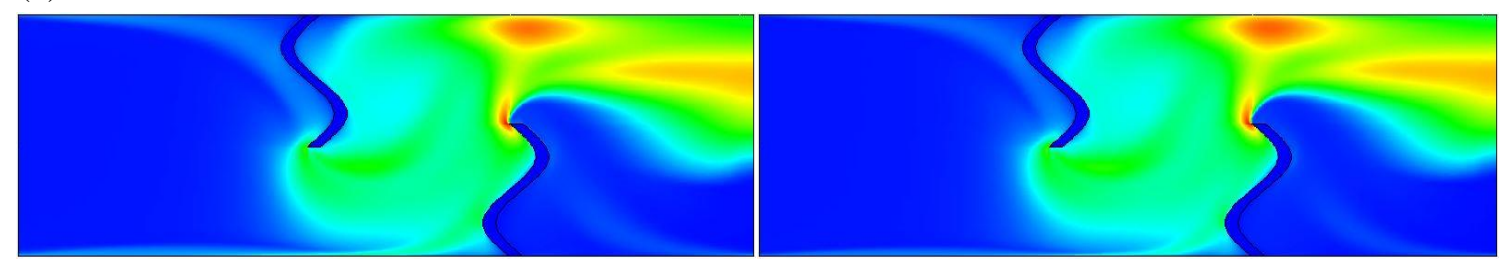

(c)
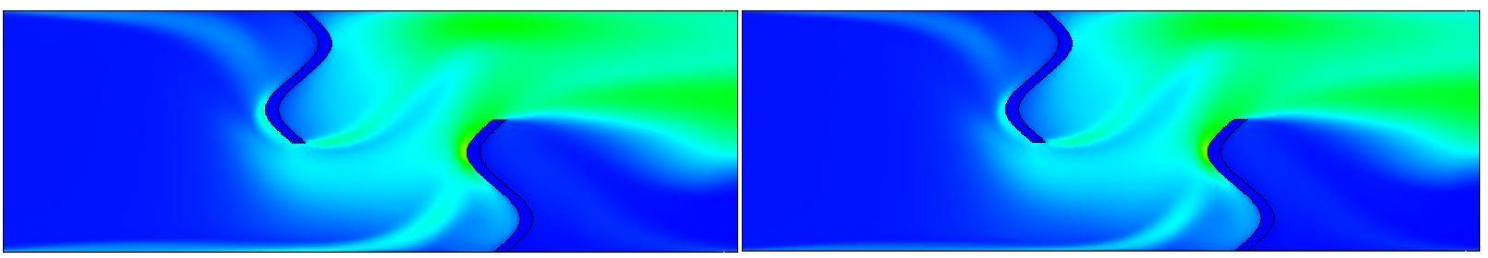

(d)

$\operatorname{Re}=12,000$

$\operatorname{Re}=32,000$

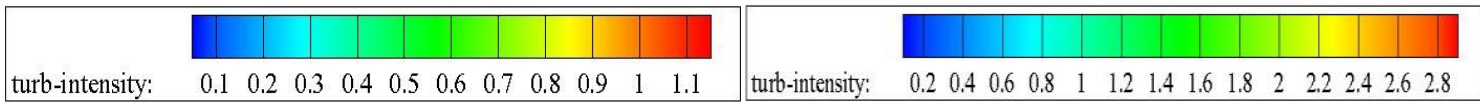

Figure 12. Turbulent intensity as a function of Re for: (a) smooth channel, (b) flat baffled channel, (c) S-upstream baffled channel, and (d) S-downstream baffled channel. Turbulent intensity values in $\%(\times 100)$.

The upper turbulent intensity values near the tip of the second baffle are due to the high velocities in that region. However, it is worth noting that for both $\mathrm{Re}$ values investigated the S-upstream configuration provides the highest turbulent intensity value. In the case of a simple baffle, the maximum value of the turbulent intensity is $249.763 \%$. This value can be decreased or increased. This is related to the geometry of the investigated baffle. This value decreases to $195.692 \%$ in case of S-downstream baffles. This diminution represents $21.648 \%$. While there is an increase in turbulent intensity values up to $302.952 \%$ in the case of S-upstream baffles. Or, $21.295 \%$ larger than in the case of a simple flat rectangular baffle. Moreover, by comparing the different baffles, the S-upstream baffle gives the highest value in the turbulent intensity by about $17.556 \%$, and 35.404 $\%$ compared to the simple flat rectangular, and S-downstream baffles, at the same upper value of Reynolds number, $\operatorname{Re}=32,000$. For comparison, the turbulent intensity at this same upper $\operatorname{Re}$ number for the case with no baffle is $52.019 \%$.

\section{Isotherms}

The temperature contours are plotted in Figure 13 (a)-(d) for smooth, flat, S-upstream, and Sdownstream baffled channel cases, respectively. One can easily notice, on the figure, that the temperature changes significantly over the hot walls of the channel for all baffled channel cases investigated. 


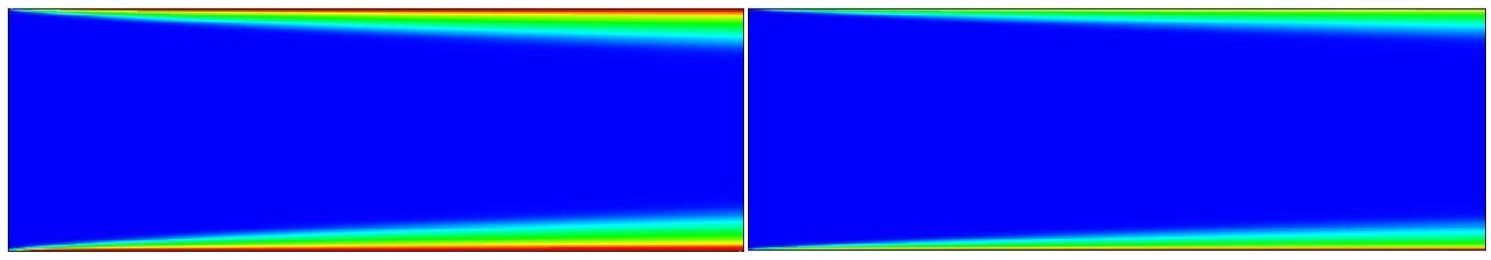

(a)

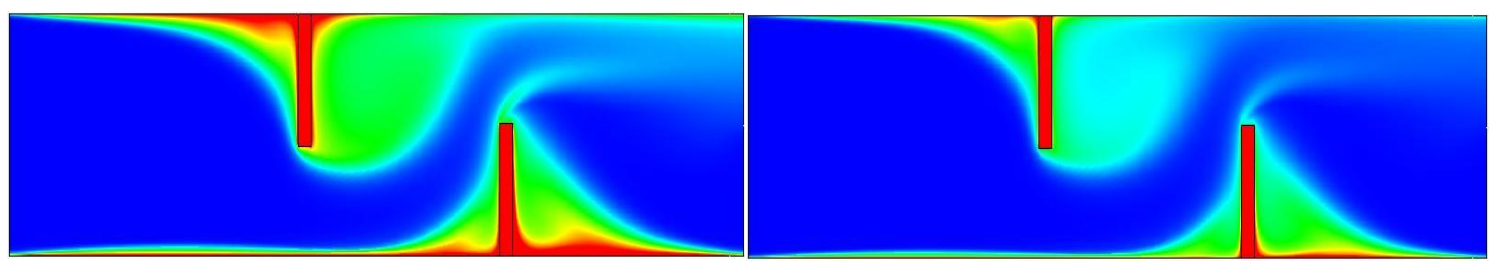

(b)

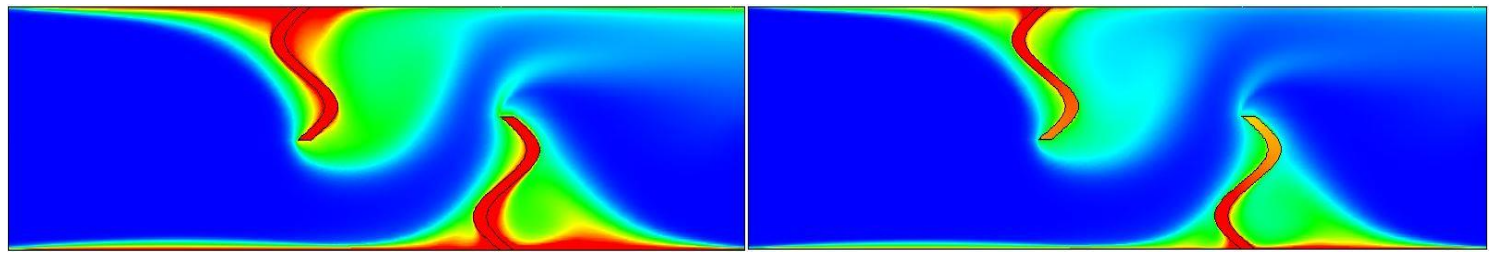

(c)
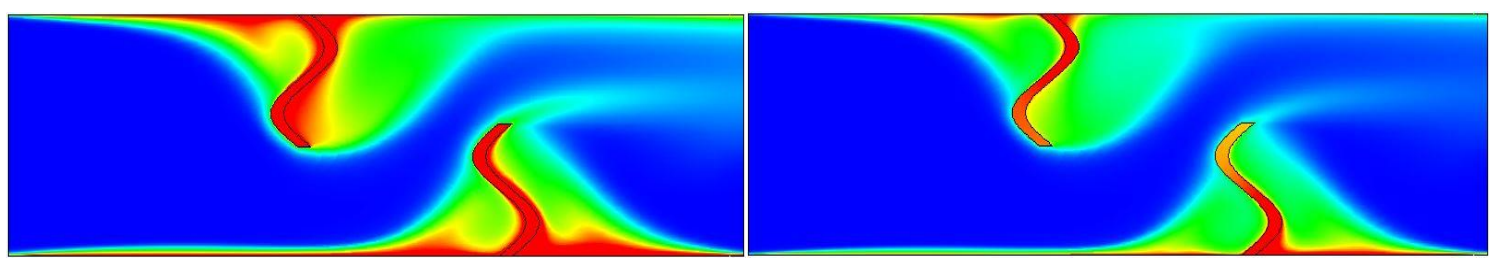

(d)

$\operatorname{Re}=32,000$

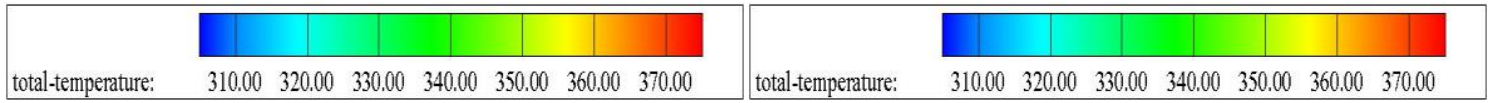

Figure 13. Isotherms as a function of Re for: (a) smooth channel, (b) flat baffled channel, (c) Supstream baffled channel, and (d) S-downstream baffled channel.

This suggests that the temperature field is considerably influenced by the recirculation flows as it can cause better mixing of the fluid in the area between the hot surfaces and the core flow regions; this should result in a high temperature gradient over the hot surfaces. In addition, the thermal field is also affected by the Reynolds number. It can be noted from this figure that for large Re values, temperatures rise importantly. Hence, one can assert that the Re value increase is inversely proportional to the temperature of the fluid in each cross-sectional part of the channel.

\section{Thermal Heat}

The local Nusselt number $\left(\mathrm{Nu}_{\mathrm{x}}\right)$ for Simple [8], S-upstream, and S-downstream cases normalized by the Nusselt number $\left(\mathrm{Nu}_{0}\right)$ of no baffle case is shown in Figure 14 as a function of the hot upper channel wall length at different Reynolds numbers of 12,000, 17,000, 22,000, 27,000 and 32,000. For all cases, the local Nusselt number is minimal in the region around the first obstacle; it is maximal in the region opposite to the second obstacle, which is the case of the configuration under study. In the intermediate zone, significant values are found, due to the recirculation of the fluid, downstream of the first obstacle. Upstream of the first obstacle, low values are found; this is due to the change in the direction of flow, caused by this same obstacle, towards the lower part of the channel, with high velocities. The local Nusselt number is also affected by the Reynolds number. A linear increment exists between the local Nusselt number and the Reynolds number for all baffle case treated. The local thermal transfer rates obtained from the simple baffle, S-shaped baffle 
pointing upstream, and S-shaped baffle pointing downstream are around 91.244, 112.862, and 85.960 times over the smooth rectangular air channel with no baffle, respectively. As expected, the $\mathrm{Nu}_{\mathrm{x}} / \mathrm{Nu}_{0}$ ratio obtained from the S-upstream baffle is substantially higher than that from the $\mathrm{S}$ downstream one for all Reynolds number used. The maximum local Nusselt number for the obstacle with S-upstream form is found to be higher by about $19.154 \%$ and $23.836 \%$ over the rectangular channels with flat rectangular [8] and S-downstream baffles, respectively.

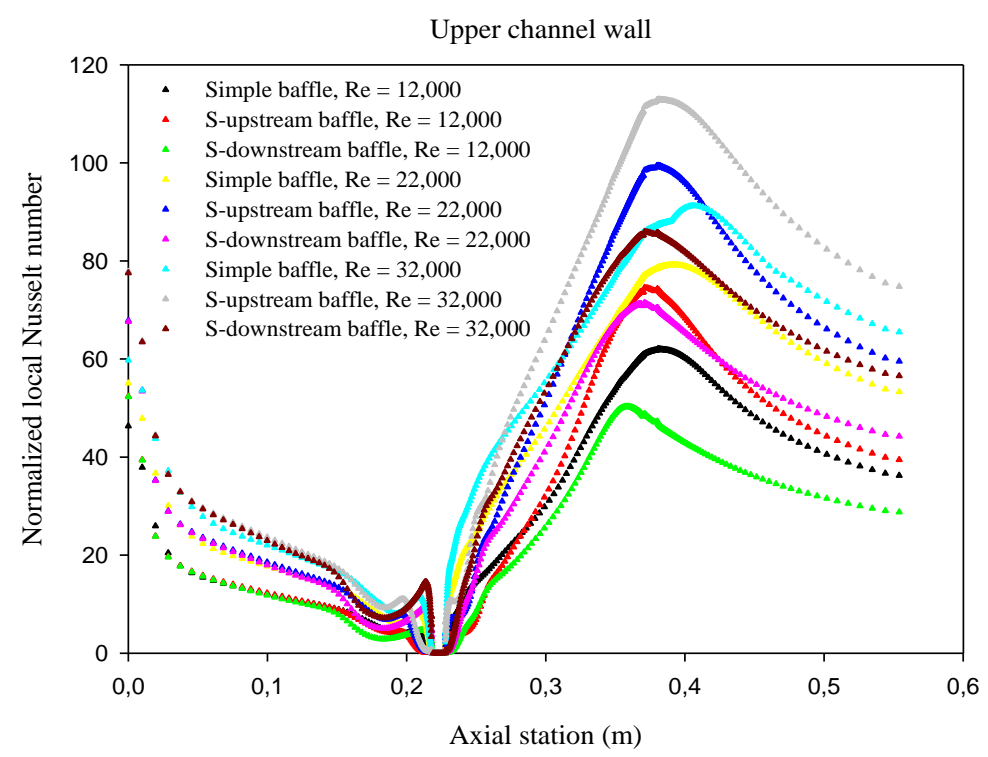

Figure 14. Variation of normalized local Nusselt number along the upper channel wall for different baffle types and Reynolds numbers.

Figure 15 shows the variations of the normalized average Nusselt number $\left(\mathrm{Nu} / \mathrm{Nu}_{0}\right)$ with the flow rate in terms of the Re number at different baffled channel cases. In the figure, the $\mathrm{Nu} / \mathrm{Nu}_{0}$ rate tends to augment with the augmentation of the Re value from 12,000 to 32,000 for all baffle models. The baffle in $\mathrm{S}$-upstream case provides upper $\mathrm{Nu} / \mathrm{Nu}_{0}$ ratio than the one in $\mathrm{S}$-downstream case around $25.011 \%$, and $19.414 \%$ for $\mathrm{Re}=12,000$, and 32,000, respectively. In both S-baffle cases, the baffled duct airflows give upper $\mathrm{Nu}$ values than that for smooth rectangular duct air flow due to the induction of high re-circulation in the baffled duct, leading to upper gradients of temperature. In the range under study, normalized average Nusselt number is found around 1.9394.582, depending on S-baffle orientations and Reynolds number. The value of $\mathrm{Nu}$ is around 2.586, and 4.582 times upper than the smooth rectangular duct in the absence of baffles and fins for $\operatorname{Re}=$ 12,000 , and 32,000, respectively, for case of S-upstream, while around 1.939, and 3.692 times for case of S-downstream. In a comparison with the flat rectangular baffle (simple obstacle) [8], the $\mathrm{Nu} / \mathrm{Nu}_{0}$ value increases in the baffle case of S-upstream model by $14.854 \%$ at $\mathrm{Re}=32,000$. However, the $\mathrm{Nu} / \mathrm{Nu}_{0}$ value decreases by $7.444 \%$ when the baffle model is S-downstream, at the same upper value of Reynolds number. 


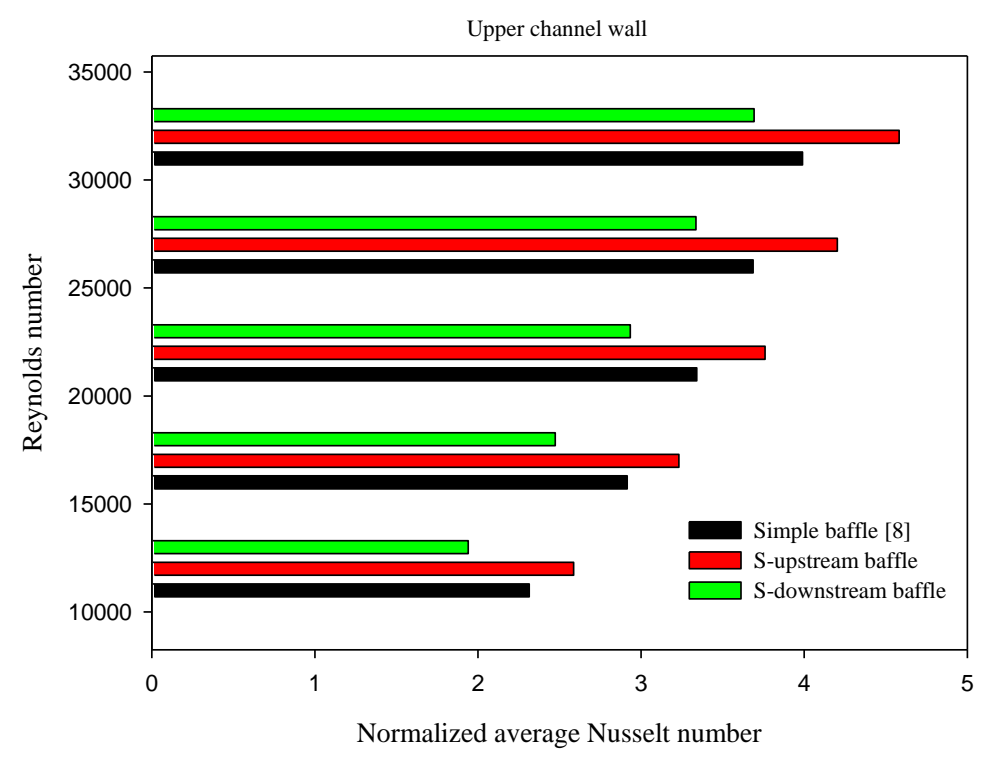

Figure 15. Variation of normalized mean Nusselt number with Reynolds number for different baffle models.

\section{Frictions}

Figure 16 depicts the skin friction coefficient, Cf along the upper channel wall for different Reynolds number values in the cases of different baffles, i.e., simple [8], S-upstream and Sdownstream. The smallest skin friction coefficient is found around the first baffle; the largest one is encountered in the region facing the second baffle, which represents the situation of the configuration under study. Note that at the starting out of the test section, the coefficient of skin friction decreases significantly because of the first baffle that is placed in the top part of the channel. In this case, the air has the possibility to flow in the direction of the bottom surface and as a result the contact between air and the upper wall of the channel is negligible. Nevertheless, the skin friction coefficients are larger again at the positions corresponding to the flow recirculation areas, as displayed in the figure. The baffles placed on the top and bottom walls cause the flow direction to change, and consequently the largest values of the skin friction coefficient come out in the recirculation region after the second baffle. It is worth mentioning that an acceleration process begins right after the first and the second baffles. The introduction of S-baffle pointing upstream provides a maximum skin friction coefficient while the S-baffle pointing downstream gives a minimum for almost axial positions. The skin friction coefficient for the S-upstream baffle is found to be higher by about $23.376 \%$ over the flat rectangular baffled channel [8] at the upper Re number while by about $59.844 \%$ above the S-downstream baffle at the same upper value of Re number as can be seen in Figure 16. Also, it is interesting to show that the skin coefficient of normalized friction tends to augments with the augmentations of Re values for all treated channel cases. The augmentation in skin friction coefficient of employing the S-upstream/downstream baffles and the simple one is in a range of 485.521 to 1209.115 times over the smooth rectangular channel. 


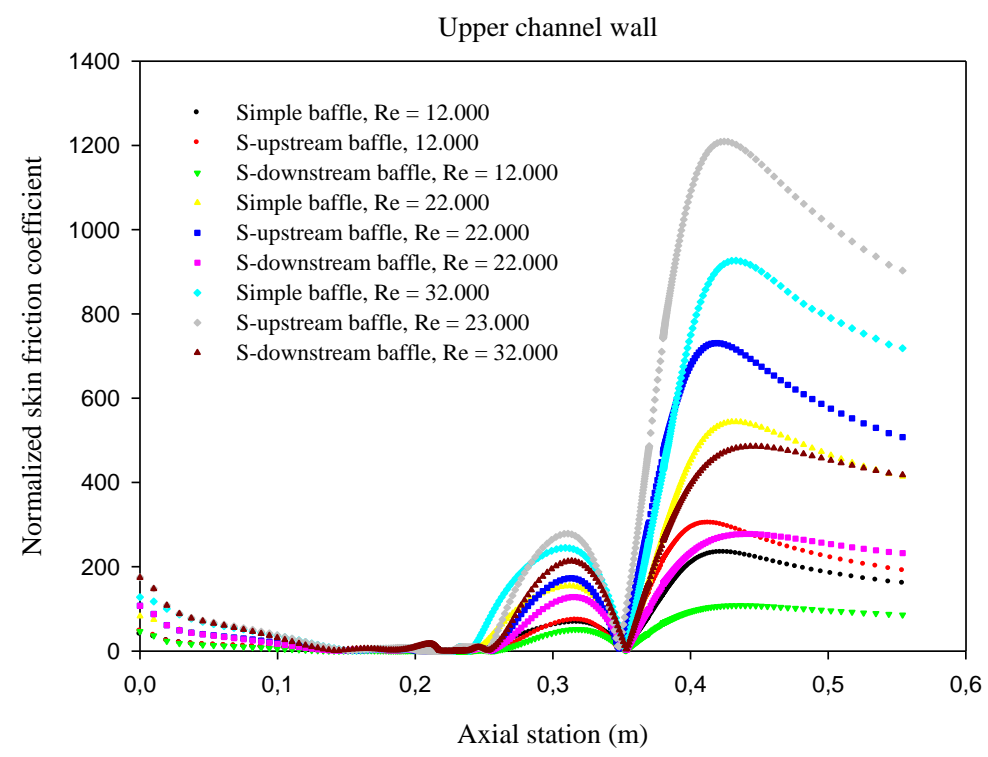

Figure 16. Variation of normalized skin friction coefficient along the upper channel wall for different baffle geometries and Reynolds numbers.

Figure 17 shows the variations of the normalized friction factor $\left(f / f_{0}\right)$ with the Reynolds number at various baffle models. In general, the $f / f_{0}$ value augments with augmenting the Reynolds number. The friction loss of S-downstream baffle is lower than that of S-upstream baffles, which indicates that the S-downstream is more advantageous than the other. At Reynolds numbers of 12,000, $17,000,22,000,27,000$ and 32,000 , the $S$-downstream baffles seemed to decrease the $\mathrm{f} / \mathrm{f}_{0}$ ratio by about, respectively, $56.443 \%, 55.700 \%, 54.972 \%, 54.289 \%$, and $53.660 \%$ relative to the Supstream baffles. The augmentation in the friction factor (f) for the $S$-baffles with both orientations is much higher than that for the smooth rectangular air channel. The $\mathrm{f} / \mathrm{f}_{0}$ values for both the $\mathrm{S}$ pointing downstream and the simple [8] baffle are around $53.660 \%$ and $20.812 \%$ lower than that for the $S$ pointing upstream. The $f / f_{0}$ value is around $6.103-25.606,7.621-32.336$ and $3.319-$ 14.984 times above the smooth rectangular channel for the S-upstream, S-downstream, and simple baffles, respectively.

\section{Thermal Enhancement Factor}

Figure 18 shows the evolution of the thermal enhancement factor (TEF), calculated by Equation (16), as a function of Reynolds number $(\operatorname{Re}=12,000,17,000,22,000,27,000$, and 32,000) with a constant section of the channel for the lower surface of the hot upper wall of the channel. 


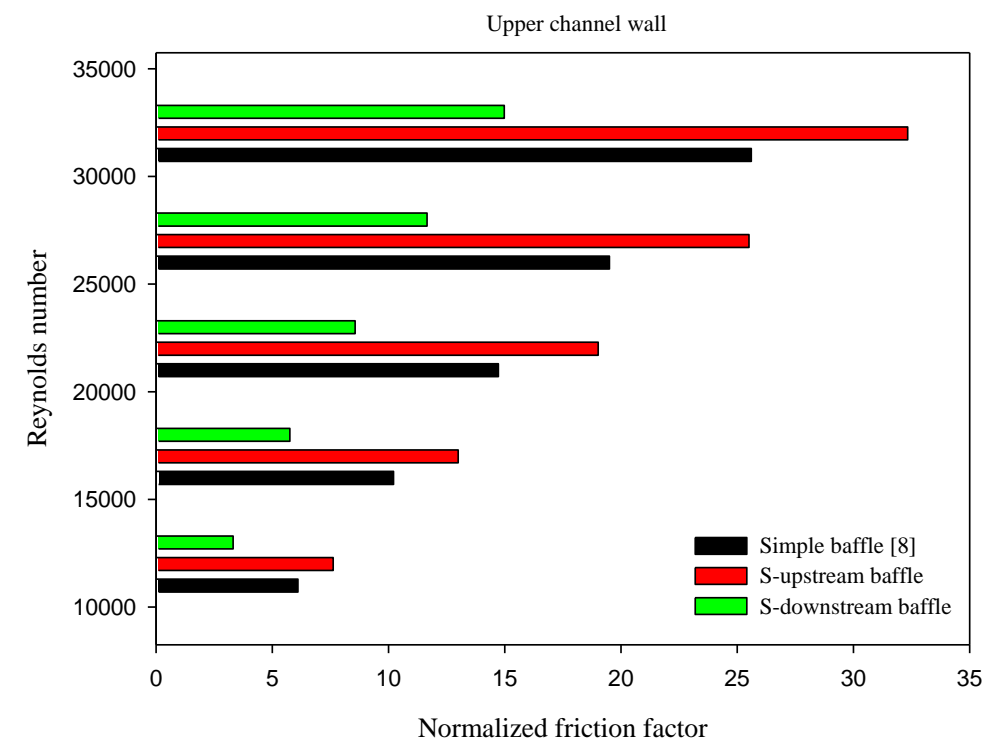

Figure 17. Variation of normalized friction factor with Reynolds number for different baffle configurations.

Two 'S'-shaped baffles, having different orientations, i.e. 'S'-upstream and 'S'-downstream, were inserted into the channel and fixed to the top and bottom walls of the channel, in a periodically staggered manner to develop vortices to improve the mixing and consequently the heat transfer. Also, a typical flat rectangular obstacle [8] is introduced for comparison.

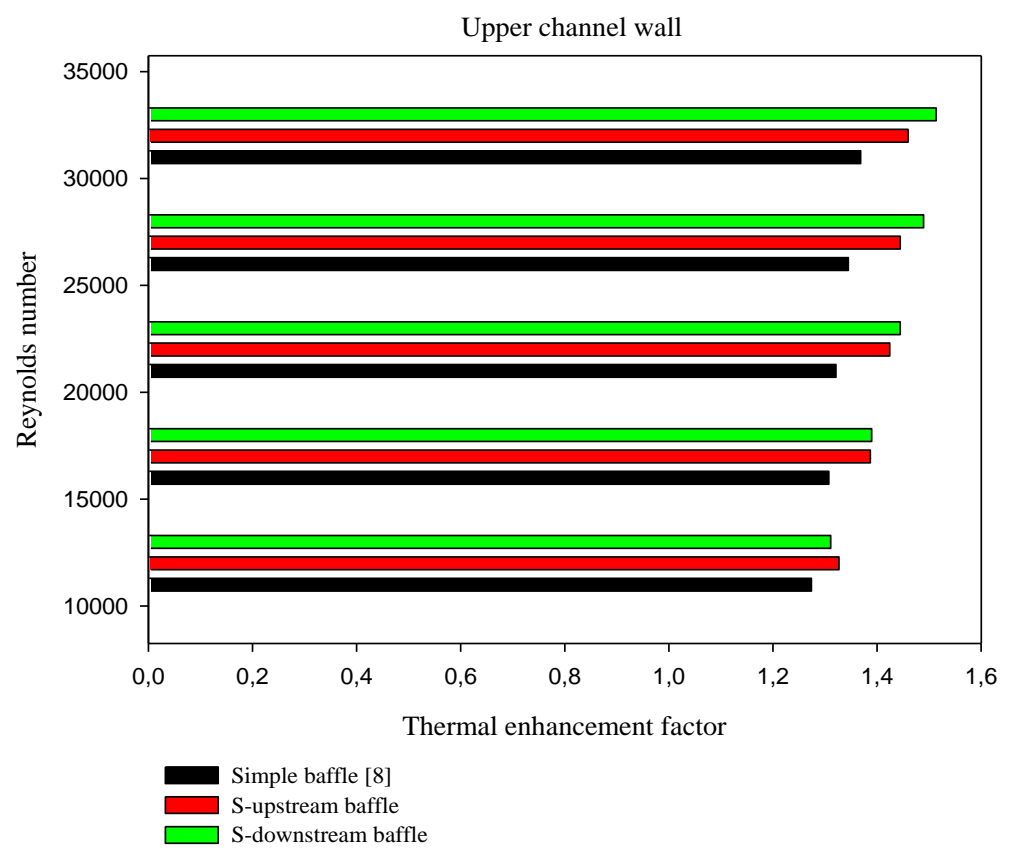

Figure 18. Thermal enhancement factor for various baffles.

As expected, the thermal enhancement factor increases with the increase in the Reynolds number in both studied cases (S-upstream and S-downstream). The TEF values range from 1.326 in the case of S-upstream baffle for the lowest value of the Reynolds number $(12,000)$, to 1.513 in the case of Sdownstream for the maximum value of the Reynolds number $(32,000)$. It is observed that the TEFs for the S-downstream baffle generally are found to be above unity and to be much higher than those for employing the $S$-upstream baffle at similar flow conditions. This indicates that the use of the $S$ downstream baffle leads to the advantage over that of the S-upstream ones. In addition, the TEF 
values of the channel equipped with the S-upstream, and S-downstream baffles are higher those that of the plain channel with a simple baffle [8] up to $6.651 \%$ and $10.605 \%$, at the highest value of Reynolds number, respectively.

\section{CONCLUSIONS}

Numerical analyses have been carried out to examine turbulent airflow and heat transfer characteristics in rectangular cross section channels fitted with various models of S-shaped baffles, i.e., S-baffles pointed towards the upstream end: called S-upstream baffles; and S-baffles pointed towards the downstream end: called S-downstream baffles, for the turbulent regime, Reynolds number of 12,000 to 32,000. Typical flat rectangular obstacles are inserted for comparison. The most important conclusions that can be drawn from this study are:

The present numerical results in terms of axial velocity and dynamic pressure profiles were compared with the experimental ones found in the literature. This comparison indicates that a qualitative agreement and a very good concordance exist between the two results.

The results obtained in the present smooth rectangular channel agree pretty well within the range + $3.5 \%$ in comparison to Dittus-Boelter correlation for the $\mathrm{Nu}_{0}$, and - $1.15 \%$ in comparison to Petukhov correlation for $\mathrm{f}_{0}$.

Important deformations and large recirculation regions were observed in the flow field. Typically, the intensity of the vortices depends heavily on the functioning parameters of the S-model under consideration. It is widely admitted that their lengths are directly proportional to the Reynolds number.

The present flow structure has significant influences on the temperature field distributions in the entire domain under investigation. The hottest regions are generally located in the neighborhood of the heated top surface and the tips of the S-baffle.

The largest value of the axial variations of the Nusselt number and skin friction coefficient is found in the region facing the second S-baffle, while the smallest value is in the region near the first $\mathrm{S}$ baffle.

The channel containing the S-obstacles with a large Reynolds number gave higher heat transfer, friction loss, and thermal enhancement factor than the one with a smaller Reynolds number.

For using the S-baffles, it is observed that the TEFs for the S-downstream baffle generally are found to be above unity and to be much higher than those for employing the S-upstream baffle at similar flow conditions.

The TEF values of the channel equipped with the S-upstream, and S-downstream baffles are higher those that of the plain channel with a simple baffle [8] up to $6.651 \%$ and $10.605 \%$, at the highest value of Reynolds number, respectively. This indicates that the use of the S-downstream baffle leads to the advantage over that of the S-upstream ones.

This simulation can be applied in improving the thermal efficiency of heat exchangers as well as solar air baffled channel collectors and electronic packages.

\section{REFERENCES}

[1] Ben Slama R. The air solar collectors: Comparative study, introduction of baffles to favor the heat transfer. Solar Energy. 2007;81:139-149.

[2] Menni Y, Azzi A, Chamkha A. Enhancement of convective heat transfer in smooth air channels with wall-mounted obstacles in the flow path. Journal of Thermal Analysis and Calorimetry. 2018. https://doi.org/10.1007/s10973-018-7268-x

[3] Kelkar KM, Patankar SV. Numerical prediction of flow and heat transfer in a parallel plate channel with staggered fins. Journal of Heat Transfer. 1987;109: 25-30. 
[4] Menni Y, Azzi A, Didi F, Harmand S. Computational fluid dynamical analysis of new obstacle design and its impact on the heat transfer enhancement in a specific type of air flow geometry. Computational Thermal Sciences. 2018;10:5:421-447.

[5] Hwang RR, Chow YC, Peng YF. Numerical study of turbulent flow over two-dimensional surface-mounted ribs in a channel. International Journal for Numerical Methods in Fluids. 1999;37:767-785.

[6] Menni Y, Azzi A, Chamkha AJ. A review of solar energy collectors: models and applications. Journal of Applied and Computational Mechanics. 2018. dio: 10.22055/JACM.2018.25686.1286.

[7] Habib MA, Mobarak AM, Sallak MA, Hadi EAA, Affify RI. Experimental investigation of heat transfer and flow over baffles of different heights. Journal of Heat Transfer. 1994;116:363-368.

[8] Menni Y, Azzi A. Design and performance evaluation of air solar channels with diverse baffle structures. Computational Thermal Sciences. 2018;10:3:225-249.

[9] Bergeles G, Athanassiadis N. The Flow past a surface-mounted obstacle. Journal of Fluids Engineering. 1983;105:461-463.

[10] Menni Y, Azzi A, Zidani C. Computational analysis of heat transfer and fluid flow characteristics over flat bars of different heights. Revue des Energies Renouvelables. 2016;19:3:345-366.

[11] Promvonge P, Sripattanapipat S, Kwankaomeng S. Laminar periodic flow and heat transfer in square channel with $45^{\circ}$ inline baffles on two opposite walls. International Journal of Thermal Sciences. 2010;49:963-975.

[12] Liu H, Wang J. Numerical investigation on synthetical performances of fluid flow and heat transfer of semiattached rib-channels. International Journal of Heat and Mass Transfer. 2011;54:575-583.

[13] Mellal M, Benzeguir R, Sahel D, Ameur H. Hydro-thermal shell-side performance evaluation of a shell and tube heat exchanger under different baffle arrangement and orientation. International Journal of Thermal Sciences. 2017;121:138-149.

[14] Menasria F, Zedairia M, Moummi A. Numerical study of thermohydraulic performance of solar air heater duct equipped with novel continuous rectangular baffles with high aspect ratio. Energy. .2017. doi: 10.1016/j.energy.2017.05.002.

[15] Mokhtari M, Gerdroodbary MB, Yeganeh R, Fallah K. Numerical study of mixed convection heat transfer of various fin arrangements in a horizontal channel. Engineering Science and Technology. 2017;20:1106-1114.

[16] Sahel D, Ameur H, Benzeguir R, Kamla Y. Enhancement of heat transfer in a rectangular channel with perforated baffles. Applied Thermal Engineering. 2016. http://dx.doi.org/doi: 10.1016/j.applthermaleng.2016.02.136.

[17] Yongsiri K, Eiamsa-ard P, Wongcharee K, Eiamsa-ard S. Augmented heat transfer in a turbulent channel flow with inclined detached-ribs. Case Studies in Thermal Engineering. 2014;3:2014:1-10.

[18] Ary BKP, Lee MS, Ahn SW, Lee DH. The effect of the inclined perforated baffle on heat transfer and flow patterns in the channel. International Communications in Heat and Mass Transfer. 2012;39::1578-1583.

[19] Dutta P, Hossain A. Internal cooling augmentation in rectangular channel using two inclined baffles. International Journal of Heat and Fluid Flow. 2005;26:223-232.

[20] Nuntadusit C, Wae-hayee M, Bunyajitradulya A, Eiamsa-ard S. Thermal visualization on surface with transverse perforated ribs. International Communications in Heat and Mass Transfer. 2012;39:634-639.

[21] Demartini LC, Vielmo HA, Möller SV. Numeric and experimental analysis of the turbulent flow through a channel with baffle plates. Journal of the Brazilian Society of Mechanical Sciences and Engineering. 2004;26:2:53-159. 
[22] Guerroudj N, Kahalerras H. Mixed convection in a channel provided with heated porous blocks of various shapes. Energy Conversion and Management. 2010;51:505-517.

[23] Menni Y, Azzi A. Numerical analysis of thermal and aerodynamic fields in a channel with cascaded baffles. Periodica Polytechnica Mechanical Engineering. Vol. 2018;62:1:16-25, 2018.

[24] Wang QW, Chen QY, Chen GD, Zeng M. Numerical investigation on combined multiple shell-pass shell-and-tube heat exchanger with continuous helical baffles. International Journal of Heat and Mass Transfer. 2009;52:1214-1222.

[25] Sripattanapipat S, Promvonge P. Numerical analysis of laminar heat transfer in a channel with diamond-shaped baffles. International Communications in Heat and Mass Transfer. 2009:36;32-38.

[26] Menni Y, Azzi A, Zidani C. Use of waisted triangular-shaped baffles to enhance heat transfer in a constant temperature-surfaced rectangular channel. Journal of Engineering Science and Technology. 2017;12:12:3251-3273.

[27] Skullong S, Thianpong C, Jayranaiwachira N, Promvonge P. Experimental and numerical heat transfer investigation in turbulent square-duct flow through oblique horseshoe baffles. Chemical Engineering and Processing. 2016;99:58-71.

[28] Jedsadaratanachai W, Boonloi A, Effects of blockage ratio and pitch ratio on thermal performance in a square channel with $30^{\circ}$ double V-baffles. Case Studies in Thermal Engineering. 2014;4:118-128.

[29] Menni Y, Azzi A, Zidani C, Benyoucef B. Numerical analysis of turbulent forced-convection flow in a channel with staggered 1-shaped baffles. Journal of New Technology and Materials. 2016:6:2:44-55.

[30] Menni Y, Azzi A. Computational fluid dynamical analysis of turbulent heat transfer in a channel fitted with staggered v-shaped baffles. World Journal of Modelling and Simulation. 2018;14:2:108-123, 2018.

[31] Sriromreun P, Thianpong C, Promvonge P. Experimental and numerical study on heat transfer enhancement in a channel with Z-shaped baffles. International Communications in Heat and Mass Transfer. 2012;39:945-952.

[32] Tahseen TA., Ishak M, Rahman MM. A numerical study of forced convection heat transfer over a series of flat tubes between parallel plates. Journal of Mechanical Engineering and Sciences. 2012;3:271-280.

[33] Gilani SE, Al-Kayiem HH, Woldemicheal DE. Effect of conical pin arrangement on heat transfer efficiency of a free convective solar air heater. Journal of Mechanical Engineering and Sciences. 2016;10:2:2053-2064

[34] Al-Kayiem HH, Yunus YMd. Drying of empty fruit bunches as wasted biomass by hybrid solar-thermal drying technique. Journal of Mechanical Engineering and Sciences. 2013;5: 652-661.

[35] Hing YK, Chin WM, Heikal MR. Numerical and experimental determination of wavy fintube shape factor. Journal of Mechanical Engineering and Sciences. 2014;6: 889-900.

[36] Neel Armstrong A, Muthucumaraswamy R. MHD flow past a parabolic started vertical plate with variable temperature and mass diffusion. Journal of Mechanical Engineering and Sciences. 2014;7:1251-1260.

[37] Launder BE, Spalding DB. The Numerical computation of turbulent flows. Computer Methods in Applied Mechanics and Engineering. 1974;3:269-289.

[38] Nasiruddin, Kamran Siddiqui MH. Heat transfer augmentation in a heat exchanger tube using a baffle. International Journal of Heat and Fluid Flow. 2007;28:318-328.

[39] Dittus FW, Boelter LMK. Heat transfer in automobile radiators of tubular type. University of California Publications in Engineering. Vol. 2, Berkeley, California, University of California Press, 1930. 
[40] Petukhov B. Heat transfer and friction in turbulent pipe flow with variable physical properties. Advances in Heat Transfer. 1970;6:503-564.

[41] Patankar SV. Numerical heat transfer and fluid flow. Hemisphere, New York, 1980.

[42] Leonard BP, Mokhtari S. Ultra-Sharp Nonoscillatory convection schemes for high-speed steady multidimensional flow. NASA TM 1-2568, NASA Lewis Research Center. 1990. 